\title{
Small mammal species diversity in brazilian tropical primary and secondary forests of different sizes
}

\author{
Gustavo A. B. da Fonseca ${ }^{1}$
}

\section{ABSTRACT}

This study investigated the effects of forest fragment size and habitat structure on species richness and diversity of Brazilian Atlantic forest small mammal communities. During the course of 17 months of live-trapping, a total of 57,120 trap nights accumulated in six forest plots. There were three size categories: small (60-80 ha.), medium (860 ha) and large $(35,973 \mathrm{ha})$. At each site two forest sections were selected for small mammal sampling: one in primary and another in secondary succession stage. A total of 692 individuals belonging to 19 species were trapped 1,366 times. Species diversity was measured using the Shannon-Wiener index $H^{\prime}$ and also a weighted version of this index that takes into account the number of individuals of each species trapped at the forests. The modified index was developed specifically for this study. The richest and most diverse forest for small mammals was the large secondary fragment, while the least diverse was the small mammal community of the small primary forest. Overall, species diversity is lower among primary forests, and also in forests of decreasing size. However, area sizelspecies relationship was only observed among secondary forests. It is postulated that primary forests are less complex habitats, when compared to secondary habitats in mid-stages of succession. Therefore, area size/species relationships should only be applied to conservation schemes if habitat structure is taken into account. By using multivariate regression methods in the investigation of the structural and size predictors of small mammal species diversity, it was possible to separate the effects of area size from those of habitat structure. Approximately half of the variance in small mammal species diversity between secondary forest fragments can be explained by area size, while habitat structure accounts for about $45 \%$ of the variation.

\section{INTRODUCTION}

During recent years considerable attention has been given to the Brazilian Atlantic forest ecosystem, one of the most threatened in the world (MITTERMEIER et al., 1982; FONSECA, 1985a). Estimates of remaining forest area indicate that less than $5 \%$ of the region has some

1 Departamento de Zoologia, Instituto de Ciências Biológicas, Universidade Federal de Minas Gerais. 30000, Belo Horizonte MG Brasil. 
form of forest cover (VICTOR, 1975, in ALMEIDA \& ROCHA, 1977; FONSECA, 1985a). It is possible that less than $1 \%$ of the Atlantic forest region of Brazil remains in a relatively undisturbed form (MITTERMEIER et al., 1982).

Previous studies have focused mainly on the highly endemic and diverse primate fauna (COIMBRA-FILHO \& MITTERMEIER, 1977) and on birds (WILLIS, 1979). On the other hand, the bulk of mammalian diversity, represented principally by rodents, marsupials and bats, remains largely unknown. This omission must be rectified because deforestation and other forms of habitat modification, such as lumbering and fuelwood extraction, continue to alter the mammalian communities. The vast majority of forest patches left in the region are small and disturbed. Under these circumstances second growth forests and their animal communities acquire a fundamental importance in any conservation scheme for the region and should be actively researched.

The present study will examine the effects of area size and habitat structure on the diversity of non-volant small mammals (rodents and marsupials) in several forested areas of the Atlantic region of Brazil. Rodents and marsupials are assumed to represent an identifiable major guild within the larger mammalian community. They are all relatively short-lived, have small body sizes (usually less than 1,000 gms), are mostly noctumal, have generalized diets with a high degree of overlap (FONSECA, 1988) and are not confined to higher strata of the forest.

The objective of this study was to examine how (a) modifications in habitat structure and heterogeneity and (b) the size of a forested area affect small mammal species richness and diversity. Species richness is defined only by the absolute number of species in a community. Species diversity is defined by both the number of species and the evenness of the contribution of each to the total numbers within the community. Diversity is shown to increase with the decrease in the probability that two individuals drawn from the community at random will belong to the same species. Said differently, diversity is a measure of average rarity (PIELOU, 1974; PATIL \& TAILLIE, 1982).

Local species richness and diversity in the tropics have been attributed to various factores (LEIGH, 1975; PRANCE, 1982; BOURLIERE, 1983). Leaving aside questions of historical biogeography (e.g., continental drift, patterns of speciation, paleoclimatic cycles, etc.), several explanations have been offered as to the proximate mechanism that lead to the maintenance of species diversity or to the achievement of lower rates of extinction in localized areas. Among these are investigations of the effects of environmental stability or moderate levels of disturbance on the coexistence of species (CONNELL \& SLATYER, 1977; CONNELL, 1978). Habitat structure and heterogeneity have been proposed as primary factors promoting small mammal especies diversity in tropical areas (AUGUST, 1983, 1984; FONSECA \& REDFORD, 1984).

The theory of island biogeography had, previous to that, also called attention to the effect that area size has on the number of 
species of equilibrium communities (MacARTHUR \& WILSON, 1967; MacARTHUR, 1972). According to this framework, the number of species in an area would be the result of extinction/colonization dynamics. The importance of the theory of island biogeography lies on that it was the first quantitative framework formulated to explain area-size relationships which were long-known through empirical evidence (for a review, see DARLINGTON, 1957). WILLIAMS (1964) has offered an explanation for the area-size relationship by hypothesizing that the observed increase in diversity with the size of the area reflects the addition of distinct habitats and its species componentes to the samples. However, the experimental design of the present study does not lend itself to traditional island biogeographical analysis because only 6 ha. of each forest were sampled, and not the total area studied. Nonetheless, we should expect larger areas to support more diversity per unit area because of lower overall extinction rates, which is in conformity with the theory's predictions.

It is also possible to survey for the causes for the presence or absence of particular species from local areas basing the investigations on the microhabitat characteristics of the species and their competitive interactions within the communities (DUESER \& SHUGGART, 1978; HALLETT et al., 1983; DUESER \& PORTER, 1986; see also FONSECA, 1988). Although that is a valid question, the main purpose of the present study was to find predictor variables that can be instrumental in explaining variation in species diversity of small mammal communities as function of habitat structure and area size, as well as at the same time conveying biological meaning.

Only one study has dealt quantitatively with the effects of the reduction of size and the isolation of patches on small mammal community characteristics in evergreen neotropical forests (MALCOLM, 1987). Other studies have provided data on small mammal ecology of several tropical ecosystems, from savanna type vegetation to evergreeri forests (FLEMING, 1971; 1975a; ALHO, 1981; FONSECA \& REDFORD, 1984; ALHO et al., 1986; EMMONS et al., 1983; AUGUST 1983, 1984; DELANY, 1986; NITIKMAN \& MARES, 1987; ISABIRYEBASUTA \& KASENENE, 1987; LACHER \& ALHO, in press; LACHER et al., in press). These areas, however, were mostly characterized by comparatively lower small mammal diversity. Communities of small mammals in the Brazilian Atlantic forest, on the other hand, are unusually rich in number of species (DAVIS, 1946; 1947; MOOJEN, 1952), thus allowing comparisons of diversity among qualitatively different areas.

\section{MATERIAL AND METHODS}

\section{The region}

This study was conducted at three sites, all located on the western 
slopes of the Brazilian Atlantic forest. Even though the western slopes of the Atlantic coastal region of Brazil are widely recognized in the literature as belonging to the major Atlantic forest formation primarily because of faunistical similarities, (MULLER, 1973; MITTERMEIER et al., 1982; FONSECA, 1983), some botanists draw a distinction betweem the eastern and the western slopes (HUECK, 1972; EITEN, 1974; ALONSO, 1977). HUECK (1972) refers to the area that contains the study sites of the present research as "subtropical forest of eastern and southern Brazil". The major distinction between the eastern and western slopes is due to a rain shadow which causes the western slopes to receive much less rainfall than the coastal slopes. The climate is characterized by a more distinct dry season, and the vegetation possesses a greater percentage of tree species showing partial deciduity during the dry season. During the rainy season, however, the forest is physiognomically very similar that found in the more wet areas. Primary forest in this region will generally have its canopy at about 20 meters and is botanically very rich (HUECK, 1972), with a well developed mid-story.

\section{Study Sites}

The three study sites are within a maximum of $300 \mathrm{~km}$ from each other and are located in the state of Minas Gerais, Brazil. All study sites can be enclosed within the boundaries of $41^{\circ}$ and $43^{\circ} \mathrm{W}$ and $18^{\circ}$ and $20^{\circ} \mathrm{S}$. All sites were of different sizes. In each, two forest patches were selected: one primary, or at least in its late successional stages, and another secondary, in all cases approximately 20 years old following clearcuting or an extensive fire. Each of the forest patches was then monitored by a 17-month live-trapping regime for small mammals.

The first site is Fazenda Esmeralda, a cattle and sugar cane farm in the country of Rio Casca, Minas Gerais. The property is bounded by the right bank of the Rio Doce and is composed of a series of valleys between several hills with a maximum of 150 meters in altitude. The farm is 4,800 ha, of which very little remain under forest. The bulk of the deforestation took place between 1964 and 1974. One approximately 80 ha patch (known as "Lagoa Fria") was in late succession and was selected as the primary forest site of the small size category. It is designated in the study as SM-PR. There are other small areas mainly covered by secondary vegetation scattered on the crowns of the several hills that occur within the farm. One of these, a 60 ha patch approximately 15-20 years old (according to the farm owner and by estimates made through physiognomic comparisons with other patches of known age) was selected. It will be hereon known as SM-SC.

Fazenda Montes Claros is located between the counties of Ipanema and Caratinga, Minas Gerais. This 1,200 ha farm has been owned by Mr. Feleciano Abdalla since 1944. Forest covers approximately 860 ha 
of the farm. The terrain is mountainous, varying between 320 and 580 meters above sea level. There are two main sections with vegetation considered as primary forest, one of which was selected, MD-PR. Another location which was under coffee and cattle pasture a few decades ago was selected as the secondary site of the middle size category, MD-SC. The two sampling locations are separated by approximately two kilometers. As the primary and secondary forests shared a common boundary, have mostly the same small mammal fauna and can potentially exchange species and individuals, all samples are considered as coming from a forest patch of similar size, or 860 ha.

The Rio Doce State Park is under the protection of the State of Minas Gerais Forest Institute (IEF). Created in 1944, the park has area of 35,973 ha. Due to its size the park is certainly the most important conservation unit for the Atlantic forest formation in the state of Minas Gerais. A major characteristic of the park is its network of 42 bog lakes. The park is almost completely covered with forest, but due to frequent fires during the 1960 's perhaps only about one-third is primary. The Rio Doce Park still contains the largest tract of primary forest left in the state. One section with tall primary forest was selected (known locally as "Campolina") and will be referred to as LG-PR. A second site that burned extensively in 1967 (in the "Hotel" region of the park), LG-SC, was chosen to represent the secondary forest of the large size category. The two sampling sites are 10 kilometers apart. For the same reasons as at Fazenda Montes Claros, the trapping samples from each of the forest types are assumed as coming from a 35,973 ha forest. Given its large size, I assume that the park represents a true sample of the original faunal assemblage of the region.

\section{Trapping}

In each of the six forest plots selected for the study three 300 meters long parallel lines were cut. Lines were separated by 100 meters. Therefore, traplines sampled an area of 6 ha. In each line 16 trapping stations located 20 meters apart were established. Traps were all confined within a circle of 3.5 meter radius measured from the center of station. Each trap station had one $48 \times 15 \times 15$ centimeter Tomahawk squirrel-size live trap (Tomahawk Live Trap Co., Tomahawk, Wisconsin) located on the ground. At every other station another Tomahawk of the same size was wired above ground on branches or vines between 1 and 4 meters high. In addition to these traps, every other station possessed a mouse-sized collapsible Sherman trap (H. B. Sherman Traps, Inc., Tallahassee, FL), with alternation of ground and tree traps. Moreover, the two outermost transect lines had, at every other station, a large $80 \times 30 \times 30$ centimeter wire home-crafted live trap. Therefore, each outer line possessed 16 ground Tomahawk traps, 8 tree-bound Tomahawk traps, 4 ground and 4 tree-bound Sherman traps and 8 ground large wire traps. The total for each outer line was 40 traps. The midline did not have large traps, but a total of 24 Tomahawk traps and 8 Sherman 
traps. In summary, every forest site had 48 trap stations disposed into 3 transects of 16 stations each, and a total of 112 permanent based traps. With the exception of Shermans, all traps were closed at the end of each five night trapping session and left in place.Sherman traps were removed, washed, and replaced each month.

Trapping took place between June of 1985 and October of 1986. Each forest site was trapped for five consecutive nights a month. During 17 months of consecutive trapping each forest plot accumulated a total of 9,520 trap nights, or a total of 57,120 trap nights for all the six forest plots together. Fresh pineapples, oatmeal and a cotton ball soaked with a commercial codfish oil solution were used as baits. Traps were checked every morning for captures and for adequacy of bait, which was replaced as needed. For each individual captured, the following information was recorded:

1. Species.

2. Location in grid.

3. Individual identification, if already tagged with metal fish tags (Fish and small animal tag, size 1, National Band and Tag Co., Newport, Kentucky). Individuals with positive taxonomic identification were released at station where captured. If individual trapped was not readily identifiable, it would be preserved for later taxonomic identification. The only individuals which were consistently preserved as skins and skulls were representatives of Oryzomys trinitiatis and, to a lesser extent, Oryzomys fornesi. The fomer shows a high degree of variability in skin color and pattern and were considered, during field work, as belonging to more than one species. Whenever possible animals that died in the traps were also preserved.

\section{Habitat Variables}

The characterization of the habitat was conducted in an area of 3,5 meter of radius around the center of each trap station. The variables which were used are slightly modified versions of measurements that have been successfully used in other studies in the description of small mammal habitat (M'CLOSKEY, 1976; DUESER \& SHUGGART, 1978; AUGUST, 1983). At each station, information was recorded on a qualitative sliding scale between 0 (minimum score for a parameter) and 3 (maximum score for a parameter) for the following variables:

1. Percent canopy cover (CC) above trap station.

2. Percent herbaceous cover (HC) around center of trap station.

3. Interconnectedness of canopy (CXC), represented by branch to branch contact or canopy to canopy link through vines.

4. Interconnectedness of midstory (CXM).

5. Volume at canopy height (DVC), 0 representing sparse vegetation, 3 dense vegetation.

6. Volume at midstory height (DVM).

7. Volume of herbaceous vegetation (DVH). 
8. Vine density (DV).

9. Epiphyte density (DE).

10. Fallen logs within or in close vicinity of trap station (FL).

11. Litter volume at soil surface (HUM).

In addition to these, other variables were quantitatively measured:

12. Overstory height $(\mathrm{OH})$.

13. Herbaceous height, determined as the most representative height category at a trap station $(\mathrm{HH})$.

14. DBH of all woody plants with DBH greater than $3.2 \mathrm{~cm}$. The composite variable SDIAM is represented by the sum of all DBHs at a trap station.

15. HT, or the average height of all trees within trap station with DBH greater than $3.2 \mathrm{~cm}$. $3.2 \mathrm{~cm}$.

16. NTR, or number of trees within station with DBH greater than

17. NSP, the number of woody plant species at trap station. The composite variable XSP represents the average number of plant species per station at each transect trapline.

\section{Statistical Methods and Data Analysis}

\section{Dependent variables}

There were four indices of community structure under study. These reflect different but interrelated measurements of community attributes:

1. Species richness (S), or number of species recorded for each particular trapline at a forest plot during the whole course of the study.

2. Species diversity, as defined by the Shannon-Wiener diversity index $\mathrm{H}^{\prime}$, where pi values were calculated for total number of first captures during 17 months of study. This procedure, al though compounds population turnover rates, yielded the same results as monthly samples.

3. Total number of individuals (NI) observed at a particular site during the 17 months of trapping, excluding recaptures.

4. Species diversity weighted by the number of individuals trapped (WH) and defined as,

$$
W H=-\sum_{i}^{n} \text { pi ln pi } \cdot \sqrt{n i}
$$

where $\mathrm{WH}=$ weighted $\mathrm{H}^{\prime}$ and $\mathrm{ni}=$ number of individuals belonging to the $i^{\text {th }}$ species in sample. In order to detect significant statistical differences betweem species diversity index values, analysis of variance was performed, with each of the three traplines at a forest patch constituting a replicate of that particular forest. For this purpose, only first captures per forest plot were used. Analyses for differences between primary and secondary forests, as well as for the different size categories were 
performed. Differences between diversity indices with pooled samples which included all three traplines were tested with pair-wise t-tests (POOLE, 1974).

Species diversity is one of the most commonly measured community structure parameters, and has important ecological (PEET, 1974; PIELOU, 1974; MAY, 1975) and management implications (MARGULES \& USHER, 1981; HAIR, 1982; CONAT et al., 1983). Several indices have been suggested in the measurement of diversity (for a discussion, see PEET, 1974). The most commonly used index in wildlife studies is the Shannon-Wiener H' (HAIR, 1982), wich is calculated as

$$
H^{\prime}=-\sum_{i}^{n}(\text { pi ln pi), }
$$

where pi represents the proportion of individuals captured belonging to the $\mathrm{i}^{\text {th }}$ species.

Given that evenness measures are not sensitive to absolute population sizes of species, they cannot always be used as indicators of underlying community structure or as indices useful to guide conservation and management decisions. For this reason I developed a weighted version of the index (WH) that takes into consideration the population sizes of the individual species. The rationale for developing this index was to provide for the effect of population size on the probability of local extinctions. In addition to being less vulnerable to demographic/ stochastic extinction events (MacARTHUR \& WILSON, 1967; SHAFFER, 1981), larger populations also tend to be less susceptible to inbreeding depression and loss of genetic variability (SOULE, 1980; 1983). Therefore, large populations are less liable to go locally extinct and this variable should be included in a species diversity index.

Measures of species diversity that are composed of number of species and evenness, such as $\mathrm{H}^{\prime}$ and others, carry not only ecological implications but are increasingly used in conservation and management applications (e.g., "Preservation of biological diversity" concept; USHER, 1986). The use of an index that takes into account the number of individuals trapped, in addition to the relative contribution of each to the total population (such as $\mathrm{H}^{*}$ ), is certainly desirable. WH distinguishes between communities that differ in the overall population density, an impossibility with $\mathrm{H}^{\prime}$. In addition, $\mathrm{H}^{\prime}$ has always the potencial to underrate highly productive and rich communities in which a small degree of imbalance in relative proportions of species occurs.

The use of a square-root function of number of individuals trapped in the index, instead of its absolute value, serves some useful purposes. The use of an exponentially decreasing function reflects the redution in the importance that number of individuals should have on the index when species' population numbers approach high levels. As population size increases, the index becomes more sensitive to the number of species 
Vol. 6(3), 1989

and to their overall contribution to the community and less sensitive to population numbers. A basic characteristic of $\mathrm{WH}$ is that it is an index highly but not solely influenced by number of individuals. WH increases faster when the increase in total number of individuals is not very skewed toward one or a few species within the community. If this is the case, the index will hopefully preserve some of the evenness component inherited from $\mathrm{H}^{\prime}$.

There are some caveats that should be stressed before interpreting WH values. Ideally, we should be able to maintain the maximun information about $\mathrm{H}^{\prime}$ as possible, while simultaneously assessing population sizes of species. There are some cases, however, in which the WH values are not useful. A community with a few species, but with extremely high population densities, will yield WH's that are higher than communities which may have many more species, but in which population densities are low across all members of the community. Therefore, it should never be used disassociated from $\mathrm{H}^{\prime}$ and $\mathrm{S}$.

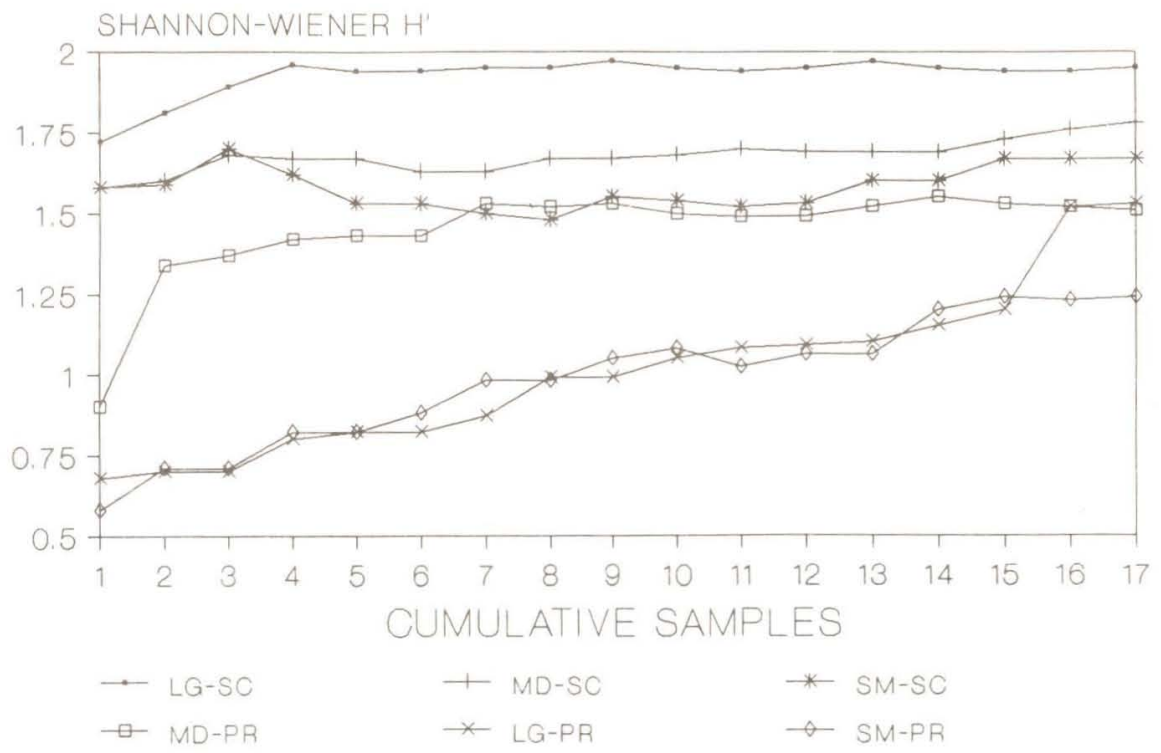

FIG. 1. Evolution in the behavior of the Shannon-Wiener $\mathrm{H}^{\prime}$ species diversity index with the increase in the number of successive samples. The legend abbreviations are as follows: $\mathrm{sm}-\mathrm{pr}=$ small primary forest; $\mathrm{md}-\mathrm{pr}=$ medium primary forest; lg-pr=large primary forest; $\mathrm{sm-sc}=$ small secondary forest; $\mathrm{md}-\mathrm{sc}=$ medium secondary forest; $\lg -\mathrm{sc}=$ large secondary forest. 


\section{WH INDEX}

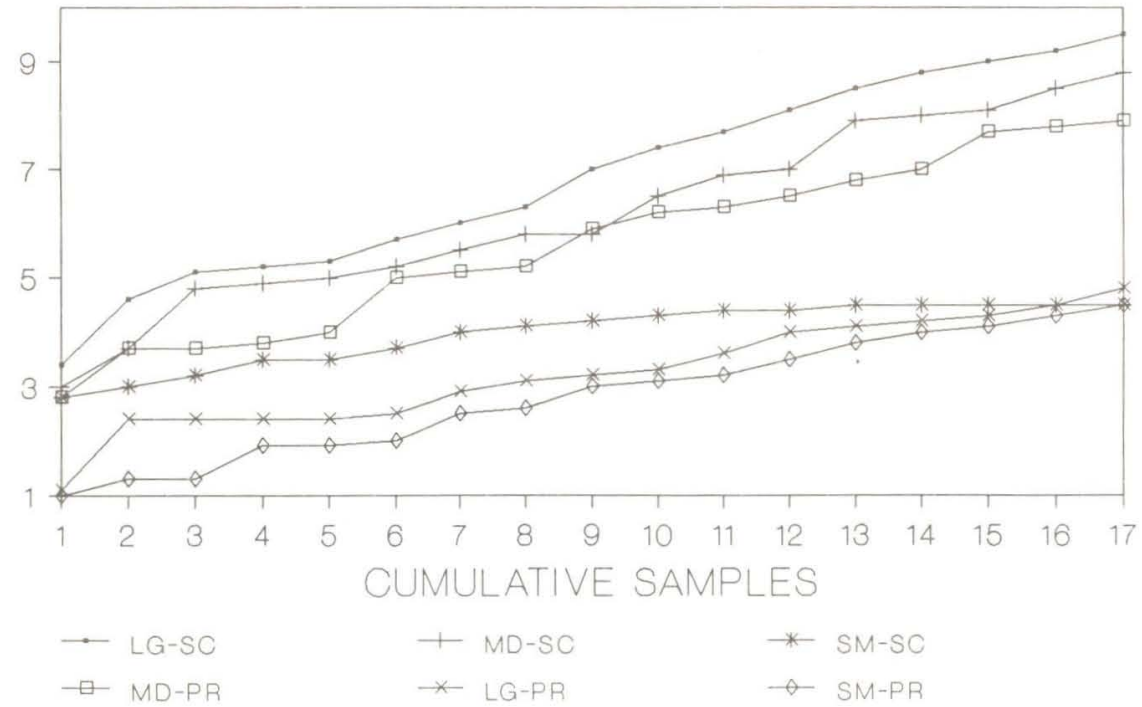

FIG. 2. Evolution in the behavior of the weighted version of the Shannon-Wiener species diversity index $(\mathrm{WH})$ with the increase in the number of successive samples. The legend abbreviations are as follows: sm-pr=small primary forests; me-pr=medium primary forest; $1 \mathrm{~g}-\mathrm{pr}=$ large primary forest; $\mathrm{sm-sc}=$ small secondary forest; md-sc=medium secondary forest; $\lg -\mathrm{sc}=$ large secondary forest.

Several simulations were performed with the index to examine its behavior under different population size conditions. All simulations that were conducted with WH were also conducted with $\mathrm{H}^{\prime}$ so as to compare them under different circumstances. In addition, I observed the fluctuation of the index values in successive samples as a further effort to estimate the reliability of the diversity measures obtained after 17 months of trapping. Examination of Figure 1 reveals that for the study period, $\mathrm{H}^{\prime}$ only becomes stable after 9-10 months of consecutive trapping. Therefore, if the study had been of shorter duration estimates of species diversity would constitute unreliable measures. WH is, on the other hand, sample dependent, i.e., will almost always increase with the addition of new samples. However, the index, as applied to the present data, showed a much more stable statistical behavior (Figure 2), for after 8 months of successive sample it kept the existing relationships constant. $\mathrm{H}^{\prime}$, on the other hand, demonstrated some statistical shifts even after 10 months of sampling, even though their relational trend was kept consistent throughout the last 7 months of the study. 


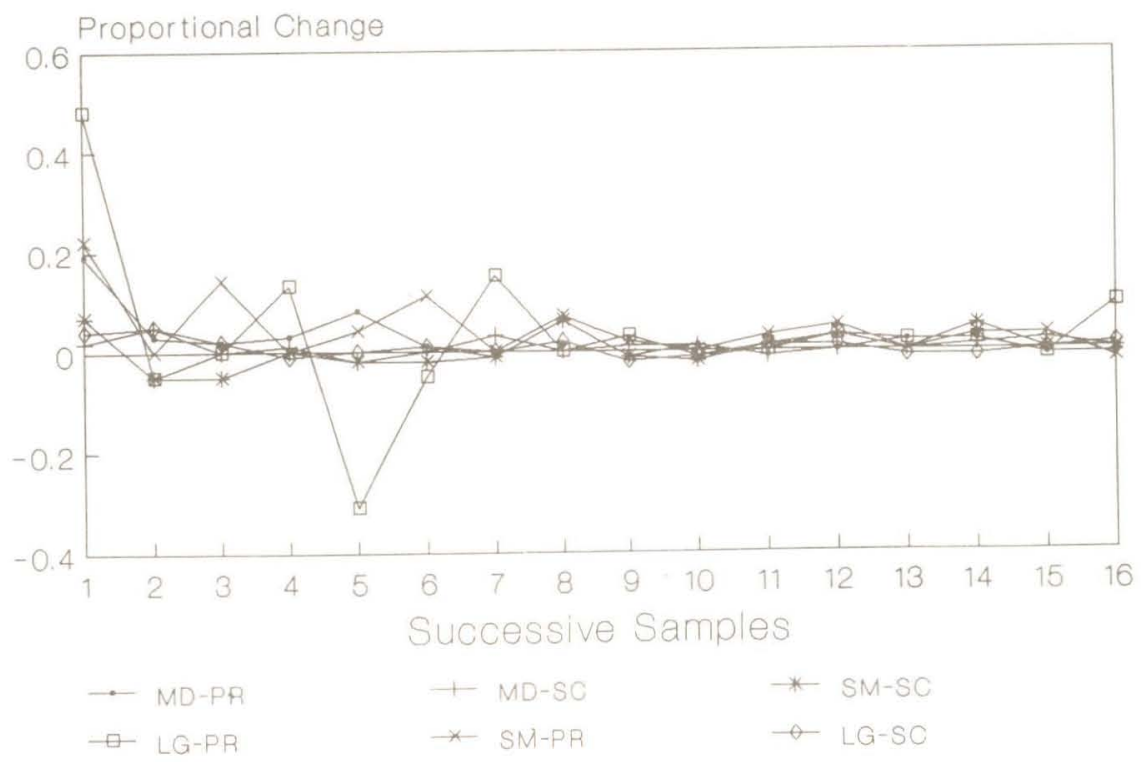

FIG. 3. Rate of change in $\mathrm{H}^{\prime}$ with the number of successive samples. The change is measured as:

Proportional Change in $H^{\prime}=\left(H^{\prime}\right.$ (next $)-H^{\prime}$ (previous) $) / H^{\prime}$ (next) The legend abbreviations are as follows: sm-pr=small primary forest; md-pr=medium primary forest; $\lg -\mathrm{pr}=$ large primary forest; $\mathrm{sm-sc}=\mathrm{small}$ secondary forest; $\mathrm{md}-\mathrm{sc}=$ medium secondary forest; $\lg -\mathrm{sc}=$ large secondary forest.

Proportional Change

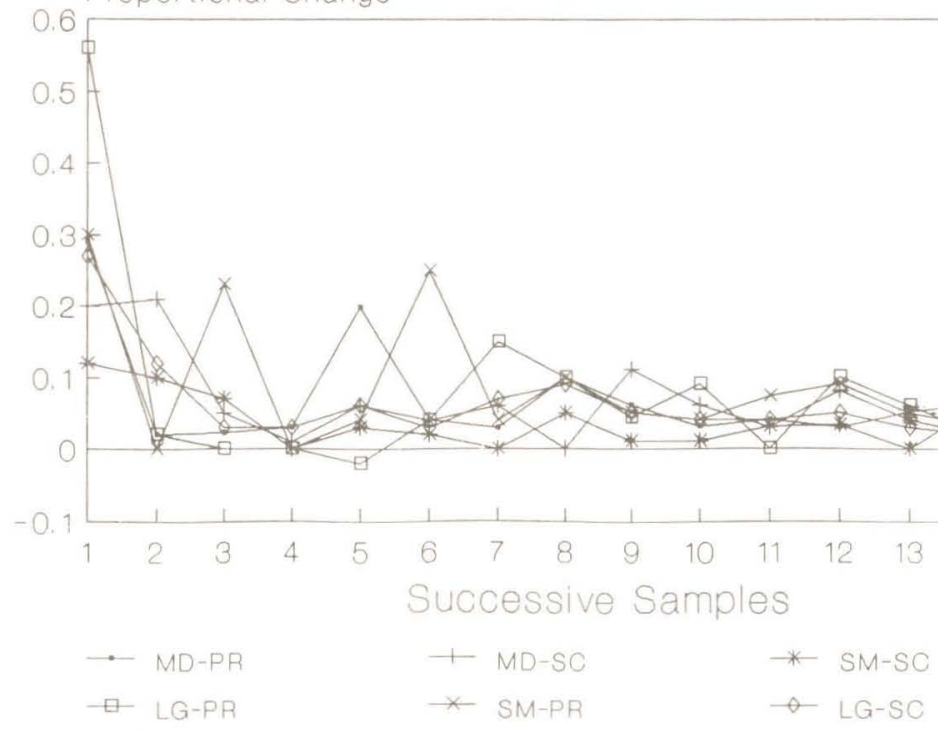

FIG. 4. Rate of change in WH with the number of successive samples. The change is measured as: 
Proportional Change in $W H=(W H(n e x t)-W H($ previous $)) / W H(n e x t)$ The legend abbreviations are as follows: sm-pr $=$ small primary forest; md-pr $=$ medium primary forest; $\mathrm{lg}-\mathrm{pr}=$ large primary forest; $\mathrm{sm}-\mathrm{sc}=$ =small secondary forest; $\mathrm{md}-\mathrm{sc}=$ medium secondary forest; lg-sc=large secondary forest.

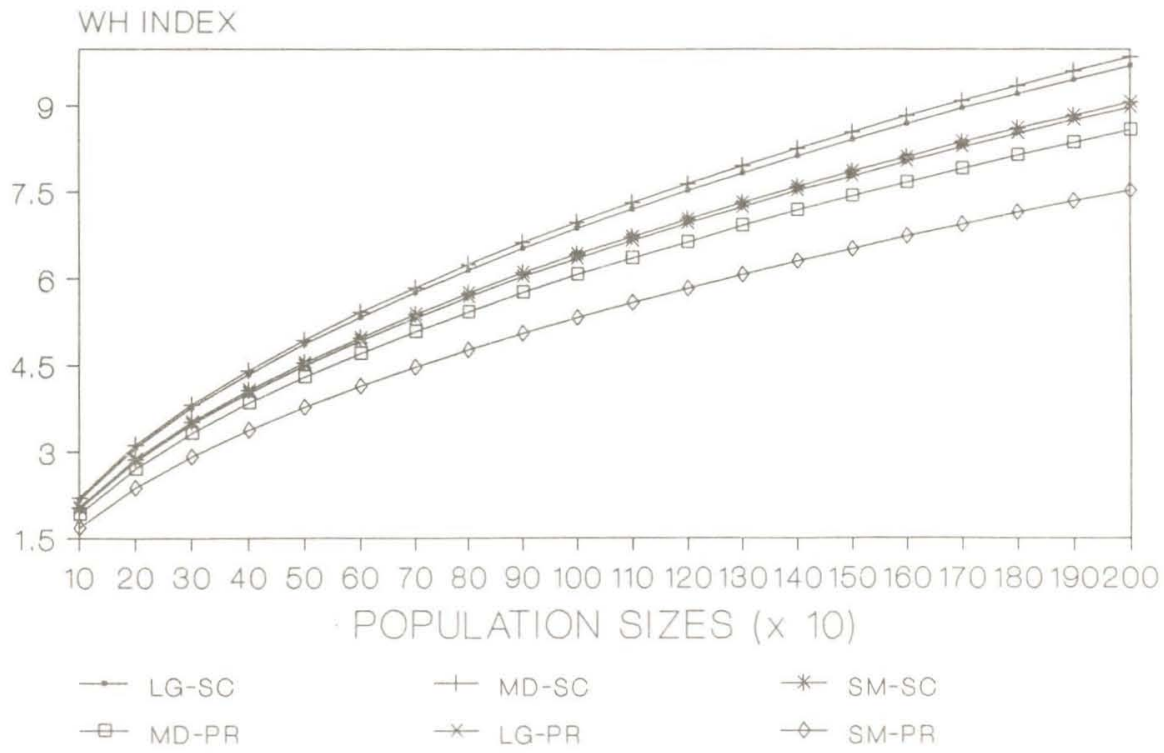

FIG. 5. Hypothetical behavior of the WH diversity index with constant increase in total population sizes of communities. The pi values (see formula in methods section) were generated using real data from this study. The legend abbreviations are as follows: sm-pr=small primary forest; $m$ d-pr=medium primary forest; $1 \mathrm{~g}$-pr=large primary forest; $\mathrm{sm-sc=small}$ secondary forest; $\mathrm{md}-\mathrm{sc}=$ medium secondary forest; $\lg -\mathrm{sc}=\operatorname{large}$ secondary forest.

Figures 3 and 4 illustrate a similar comparison examining the proportinonal change of indices from a previous sample to the next sample throughout the study period. After 9 months of consecutive trapping, $\mathrm{H}^{\prime}$ tended to stabilize, generally changing less than $5 \%$ from the previous to the next index value. With WH, even though it takes roughly the same time to reach a point of steady fluctuation, the changes can reach up to $10 \%$ from one sample to another, or twice the rate of H'. An additional difference is that, except with a very small number of samples, WH will always increase with further samples, while $\mathrm{H}^{\text {' }}$ can grow negatively from a former to a latter sample.

Another simulation that demonstrates the stable relationships of WH and its value as a measurable feature of these small mammal communities can be found in Figure 5. The graph shows the behavior of the index if we insert actual species richness and proportions to variable hypothetical population sizes. What the method provides is a 
heuristic way of looking at these different communities were their overall population sizes different for whatever reason than the actual values. We can then, to a certain degree, isolate the desirable information provided by the Shannon-Wiener diversity index, without losing the "population size" perspective.

\section{Predictors of Community S tructure}

The first step to identify predictor variables that explain variation in species richness or number of species (s), in total number of individuals captured (NI) and in species diversity $\left(\mathrm{H}^{*}\right)$, as well as in its weighted version (WH), is by the use of correlation and regression analysis. By using correlations I was able to both determine significant associations between dependent and independent variables, as well as intercorrelations between habitat predictor variables. This is important in order to avoid problems of colinearity in subsequent multiple regression analysis (SOKAL \& ROHLF, 1981; KACHIGAN, 1982). I expected that a large number of habitat variables would be intercorrelated because many similar measures were recorded.

After correlation coefficients were determined, multiple regression was applied to the reduced data in as effort to find the predictor variables that would explain significant amounts of variation in the dependent variables (S, NI, H', WH). All habitat variables that were collected as percentages were arcsin transformed and the remaining variables logtransformed to approach homoscedasticity (SOKAL \& ROHLF, 1981). A SAS-PC (SAS Institute, Cary, NC) statistical package was used in the analyses on MS-DOS (Microsoft Corporation) based machines. Multiple regressions carried out with the RSQUARE method ("maximum $\mathrm{r}^{2}$ improvement").

\section{Primary Versus Secondary Forests}

The first step on this analysis was to determine if the habitat variables collected supported the classification of the forests, conducted previously in the field, as primary and secondary. Discriminant analysis was used to classify trapping stations as belonging to either primary or secondary forests. The accuracy with the resulting discriminant function separates stations in either type of forest provides an estimate of its validity (KACHIGAN, 1982). Validity was measured by examining both the magnitude of correct classifications and the chi-square values associated with Wilks' lambda at a p-level of 0.05 .

The analyses were conducted with all data points of dependent variables taken as a whole, as well as separating individual analysis between primary and secondary forests. The objective with the first method was to determine if any existing relationships bet ween community parameters and the independent variables area size and habitat structure 
would hold regardless of forest structure. The latter method would indicate if the community parameters measured on primary and secondary forests, respectively, respond differently to independent variables.

\section{Area Size Effects}

One of the main objectives of this study was to determine the effect of area size on species richness, species diversity and total number of small mammal individuals. However, it is often difficult to separate the effects of area size from those arising from habitat structure. I approached this problem by eliminating from the analysis habitat variables that were correlated with size. Next, the remaining set of independent variables and area size were entered as regressors. The following method was emulated from Lacher et al. (in press), a study in which the objective was to separate habitat structural effects from those of species interactions. First, we noted the change in $\mathrm{r}^{2}$ when the habitat structure variables were entered in a model that already contained area size as an independent variable. Secondly, the same process was repeated, with the difference that this time area size entered a model already containing the independent habitat variables. $r^{2}$ for the full model is equal for either equation regardless of entry order. Habitat structure $r^{2}$ is the improvement in overall $r^{2}$ for the first equation, and conversely, area size $\mathrm{r}^{2}$ is represented by the change in the full model $\mathrm{r}^{2}$. This analysis provides an estimate of the percentage of variation in the full model that can be attributed to either area size or habitat structure variables.

\section{RESULTS}

During the course of the study I captured a total of 692 individuals (excluding recaptures) belonging to 19 species, 8 of them marsupials and 11 rodents (Table I). Marsupials were by far the most common small mammals in all sites examined. Marsupials were responsible for $65 \%$ and $64 \%$ of all individuals in primary and secondary forests, and $74 \%$ and $75 \%$ of all individuals in small and large plots, respectively. The only sites in which rodents appear to be almost as abundant as marsupials are in the forests of intermediate size. Approximately $47 \%$ of all individuals in the two forests taken together were rodents. The most abundant rodent species were Proechimys setosus and Oryzomys trinitatis.

Four species, Didelphis marsupialis, Metachirus nudicaudatus, Marmosa incana and Oryzomys trinitatis, occurred at all six forest sites sampled. Two others, Proechimys setosus and Philander opossum, were found in all sites of intermediate and small sizes but were conspicuously absent from the large sites. Eight of the nineteen small mammal species were only registered in one forest site, usually with two or one individuals. Marmosa cinerea, even though it only occurred in the two 
Vol. 6(3), 1989

TABLE I. Number of individuals of each species captured (no recaptures included) in the six forest plots sampled. For description of the sites, see Materials and Methods section.

\section{SPECIES}

\begin{tabular}{lrrrrrrr} 
Caluromys philander & 0 & 0 & 0 & 0 & 0 & 06 & 06 \\
Didelphis marsupialis & 41 & 18 & 40 & 30 & 11 & 04 & 144 \\
Marmosa agilis & 0 & 03 & 0 & 04 & 0 & 0 & 07 \\
Marmosa cinerea & 0 & 0 & 0 & 0 & 08 & 35 & 43 \\
Marmosa incana & 05 & 05 & 15 & 39 & 07 & 56 & 127 \\
Marmosa microtarsus & 0 & 0 & 0 & 0 & 0 & 01 & 01 \\
Metachirus nudicaudatus & 13 & 01 & 16 & 18 & 26 & 31 & 105 \\
Philander opossum & 01 & 01 & 09 & 03 & 0 & 0 & 14 \\
Abrawayomys ruschi & 0 & 0 & 0 & 0 & 0 & 01 & 01 \\
Akodon cursor & 0 & 0 & 0 & 01 & 01 & 27 & 29 \\
Nectomys squamipes & 0 & 02 & 02 & 0 & 0 & 06 & 10 \\
Oryzomys capito & 0 & 0 & 0 & 0 & 0 & 01 & 01 \\
Oryzomys nigripes & 0 & 01 & 02 & 02 & 0 & 0 & 05 \\
Oryzomys subflavus & 0 & 0 & 0 & 0 & 0 & 01 & 01 \\
Oryzomys trinitatis & 03 & 15 & 04 & 40 & 04 & 18 & 84 \\
Oxymycterus sp. & 0 & 0 & 0 & 0 & 0 & 02 & 02 \\
Rhipidomys mastacalis & 0 & 0 & 0 & 0 & 0 & 01 & 01 \\
Echymys sp. & 0 & 0 & 01 & 0 & 0 & 0 & 01 \\
Proechimys setosus & 07 & 03 & 80 & 20 & 0 & 0 & 110 \\
\hline Total n ${ }^{\circ}$ of Individuals & 70 & 49 & 169 & 157 & 57 & 190 & 692 \\
\hline Total n ${ }^{\circ}$ of Species & 06 & 09 & 09 & 09 & 06 & 14 & $19^{*}$ \\
\hline & & & & & & & \\
\hline
\end{tabular}

*Total is the number of different species pooled among all sites.

large plots, was quite common at these sites. Similarly, Akodon cursor was very common in the large secondary forest, only appearing again in the sample at the large primary and medium secondary plots, with one individual in each.

The richest site in number of species and number of individuals was the largest secondary forest, with 190 individuals belonging to 14 species. The poorer forest types in number of species were represented by the small primary forest category and by the large primary category (both with 6 species). The intermediate sizes and the small secondary forest all yielded 9 species each. 
Revta bras. Zool.

TABLE II. Shannon-Wiener diversity indices $\left(\mathrm{H}^{\prime}\right)$ and weighted diversity indices (WH) for each of the forest plots and for each transect line within forest plot. $T=$ indices for all samples taken together.

\begin{tabular}{|c|c|c|c|c|c|c|c|c|c|c|c|c|}
\hline & & $\mathrm{Sn}$ & & & & $\mathrm{Mec}$ & ium & & & $\mathrm{La}$ & & \\
\hline & $\begin{array}{r}\text { Pri } \\
\text { (S M }\end{array}$ & $\begin{array}{l}\text { nary } \\
\mathbf{P R})\end{array}$ & $\begin{array}{l}\text { Seco } \\
\text { (S M }\end{array}$ & $\begin{array}{l}\text { dary } \\
\text { SC) }\end{array}$ & $\begin{array}{l}\text { Prir } \\
\text { (MD }\end{array}$ & $\begin{array}{l}\text { aary } \\
\mathbf{P R} \text { ) }\end{array}$ & $\begin{array}{l}\text { Secor } \\
\text { (MD }\end{array}$ & $\begin{array}{l}\text { dary } \\
\text { SC) }\end{array}$ & $\begin{array}{l}\text { Pri } \\
\text { (LG }\end{array}$ & $\begin{array}{l}\text { hary } \\
\mathbf{P R})\end{array}$ & $\begin{array}{l}\text { Seco } \\
\text { (LG }\end{array}$ & $\begin{array}{l}\text { dary } \\
\text { SC) }\end{array}$ \\
\hline & $\mathrm{H}$ & WH & $\mathrm{H}$ & WH & $\mathrm{H}$ & WH & $\mathrm{H}$ & WH & $\mathrm{H}$ & WH & $\mathrm{H}$ & WH \\
\hline$\# 1$ & 1.09 & 1.67 & 1.42 & 2.59 & 1.61 & 5.24 & 1.80 & 5.67 & 1.52 & 3.21 & 1.87 & 5.72 \\
\hline$\# 2$ & 1.50 & 2.77 & 1.47 & 2.51 & 1.20 & 4.40 & 1.68 & 5.15 & 1.13 & 1.81 & 1.87 & 5.26 \\
\hline$\# 3$ & 1.34 & 2.96 & 1.43 & 2.72 & 1.30 & 3.61 & 1.50 & 4.18 & 1.49 & 3.02 & 1.93 & 5.44 \\
\hline $\mathrm{T}$ & 1.24 & 4.46 & 1.67 & 4.50 & 1.51 & 7.87 & 1.78 & 8.75 & 1.53 & 4.84 & 1.95 & 9.48 \\
\hline
\end{tabular}

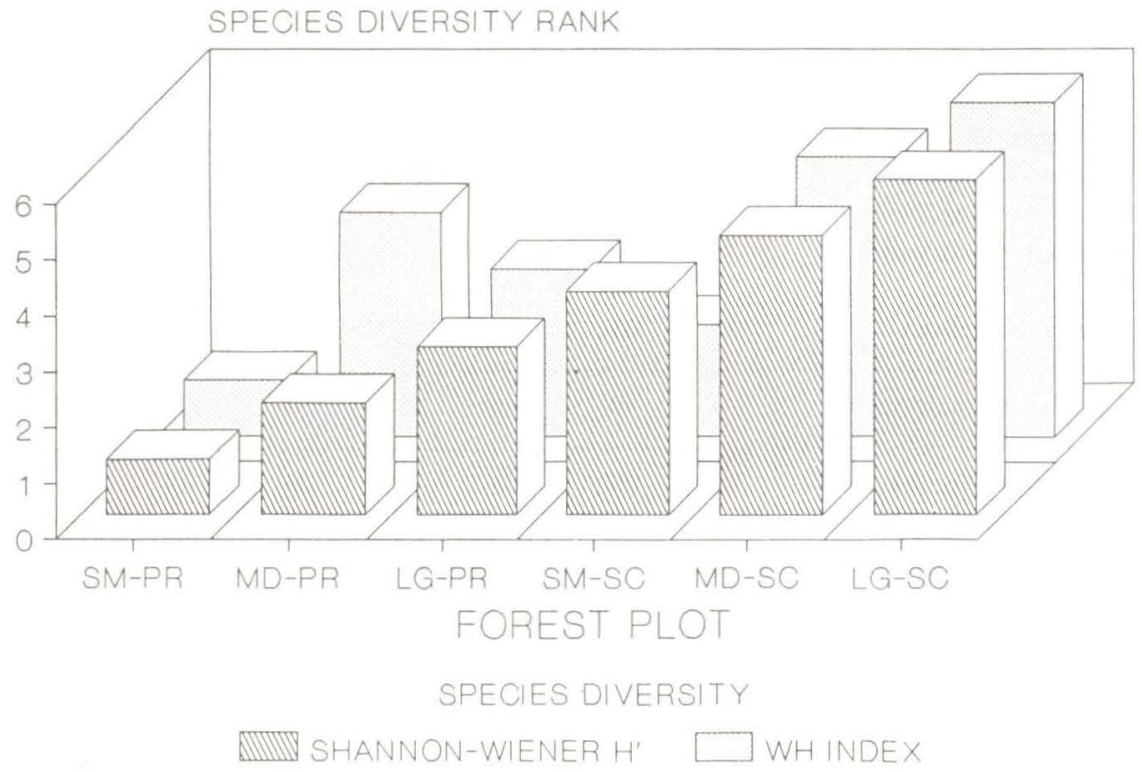

FIG. 6. Comparison of ranks of diversity indices for both Shannon-Wiener $\mathrm{H}^{\prime}$ and the its weighted version (WH). The values on the $y$ axis represent ranks and not the actual values of the diversity indices. The legend abbreviations are as follows: sm-pr=small primary forest; $\mathrm{md}-\mathrm{pr}=$ =medium primary forest; $\mathrm{lg}-\mathrm{pr}=$ large primary forest; $\mathrm{sm-sc}=$ small secondary forest; $\mathrm{md}-\mathrm{sc}=$ medium secondary forest; $\lg -\mathrm{sc}=\operatorname{large}$ secondary forest. 
All primary forests had higher H' values than secondaries, and within each class larger plots were more diverse than medium-sized, and these more diverse than the small forest sites. In Table $\amalg$, species diversity, as measured by $\mathrm{H}^{\prime}$ and $\mathrm{WH}$, are shown for each trapline, as well as the overall score for each particular forest type. The order of ShannonWiener H' indices, from lowest to highest, was as follows: Small Primary, Medium Primary, Large Primary, Small Secondary, Medium Secondary, Large Secondary (Figure 6). Of these, the first three (all secondary) were significantly different from each other, and each from all primaries (pairwise t-tests; $\mathrm{p}$ 0.05). However, for the primary forests, regardless of size, differences were not statistically significant.

WH values generally demonstrated the same trend (Figure 6): the two forest plots with the highest indices were secondary forests of medium and large sizes. The lowest score was also obtained at the smallest primary forest. However, WH ranked the medium primary forest above the small secondary. In addition, significant differences between WH values (pair-wise t-tests, $\mathrm{p}<0.05$ ) were only found between the three highest ranking forests (LG-SC, MD-SC, MD-PR) and the lowest ranking plots (SM-SC, LG-PR, SM-PR). If we scrutinize the data (see Table I) we see that the results are consistent with the sensitivity of WH. Both plots have 9 species, 8 of which are shared between the two. However, for all but one species (Oryzomys trinitiatis), the medium primary site supports much larger population sizes for the individual species. In Figure 5 we can observe that if species populations were allowed to increase at SM-SC (small secondary forest) its value would surpass that of MD-PR (medium primary) by virtue of its higher evenness between species' contribution to the whole community. It is also important to notice that the small secondary forest has three species represented by only one individual.

TABLE III. Results of the discriminant analysis separating trapping stations into primary and secondary forests (Wilk's lambda $=0.514 ; \mathrm{p}<0.001$ ). Only two classes were recognized (primary and secondary forest stations), with no discrimination for size. Therefore, initial probability of classification in either category was 0.5 .

\begin{tabular}{|c|c|c|c|c|c|c|}
\hline & \multicolumn{2}{|c|}{ Small } & \multicolumn{2}{|c|}{ Medium } & \multicolumn{2}{|c|}{ Large } \\
\hline & Primary & Secondary & Primary & Secondary & Primary & Seconadry \\
\hline$\%$ Correct & 75.0 & 98.0 & 87.5 & 81.3 & 93.4 & 83.3 \\
\hline
\end{tabular}

The resulting discriminant function varied in its power of correctly discriminating primary and secondary forests trapping stations, from a low of $75 \%$ (small primary) to a high of $98 \%$ (small secondary, Table III). Given that the initial probability of erring was $50 \%$, the forest which had the highest percentage of incorrectly classified stations still had the majority of them within the correct category. The small primary 
forest had the highest proportion of misclassified stations because of the large edge area relative to other forests. In summary, the discriminant function was generally successful in discriminating trap stations across all forest sites, and its wilks' lambda value was highly significant $(\mathrm{p}<0.0001)$.

TABLE IV. Summary statistics of habitat variables measured in the six different forest plots. A total description of the variables can be found in text. For all variables, the total number of observations is equal to the total number of trap stations in each site ( $\mathrm{N}=48)$, except where noted. All measurements (except sliding scales) are in meters.

\begin{tabular}{|c|c|c|c|c|c|c|c|c|c|c|c|c|}
\hline \multicolumn{5}{|c|}{ VARIABLES } & \multicolumn{4}{|c|}{ FOREST PLOTS } & & & & \\
\hline & \multicolumn{4}{|c|}{$\begin{array}{c}\text { Fazenda Esmeralda, Rio } \\
\text { Casca }\end{array}$} & \multicolumn{4}{|c|}{$\begin{array}{c}\text { Fazenda Montes Claros, } \\
\text { Caratinga }\end{array}$} & \multicolumn{4}{|c|}{$\begin{array}{l}\text { Parque Estadual } \\
\text { Florestal do Rio Doce }\end{array}$} \\
\hline & \multicolumn{4}{|c|}{ Small ( 80 ha / 60 ha) } & \multicolumn{4}{|c|}{ Medium (860 ha) } & \multicolumn{4}{|c|}{ Large $(35,980 \mathrm{ha})$} \\
\hline & \multicolumn{2}{|c|}{$\begin{array}{l}\text { Primary } \\
\text { (SM-PR) }\end{array}$} & \multicolumn{2}{|c|}{$\begin{array}{l}\text { Secondary } \\
\text { (S M-SC) }\end{array}$} & \multicolumn{2}{|c|}{$\begin{array}{l}\text { Primary } \\
(\text { MD-PR) }\end{array}$} & \multicolumn{2}{|c|}{$\begin{array}{l}\text { Secondary } \\
\text { (MD-SC) }\end{array}$} & \multicolumn{2}{|c|}{$\begin{array}{l}\text { Primary } \\
(\mathbf{L G}-\mathbf{P R})\end{array}$} & \multicolumn{2}{|c|}{$\begin{array}{l}\text { Secondary } \\
\text { (LG-SC) }\end{array}$} \\
\hline & Mean & SD & Mean & SD & Mean & SD & Mean & $\mathrm{SD}$ & Mean & $\mathrm{SD}$ & Mean & SD \\
\hline HT & 5.6 & 1.8 & 4.9 & 2.0 & 7.4 & 2.1 & 6.70 & 1.6 & 7.2 & 2.2 & 6.5 & 1.6 \\
\hline $\mathrm{OH}$ & 13.8 & 5.8 & 6.3 & 4.1 & 20.4 & 6.7 & 13.7 & 5.6 & 21.7 & 6.9 & 14.9 & 5.0 \\
\hline $\mathrm{HH}$ & 2.0 & 0.8 & 2.2 & 0.9 & 1.4 & 0.8 & 2.41 & 0.9 & 1.1 & 0.8 & 1.0 & 0.6 \\
\hline $\mathrm{CXC}$ & 0.8 & 1.0 & 0.1 & 0.4 & 0.9 & 0.8 & 0.44 & 0.7 & 1.4 & 0.9 & 0.7 & 0.8 \\
\hline CXM & 1.6 & 1.0 & 0.6 & 0.8 & 1.5 & 0.7 & 1.42 & 1.0 & 2.2 & 0.8 & 2.3 & 0.8 \\
\hline $\mathrm{CC}$ & 52.4 & 12.9 & 31.3 & 19.1 & 43.0 & 17.0 & 48.0 & 13.5 & 52.7 & 7.4 & 51.6 & 10.0 \\
\hline $\mathrm{HC}$ & 51.8 & 12.0 & 48.5 & 12.9 & 38.3 & 15.0 & 51.9 & 11.2 & 56.9 & 7.1 & 40.3 & 17.3 \\
\hline DVC & 1.2 & 0.9 & 0.3 & 0.5 & 0.9 & 0.8 & 0.79 & 0.9 & 1.5 & 0.9 & 1.2 & 0.8 \\
\hline DVM & 1.7 & 0.9 & 0.9 & 1.0 & 1.9 & 0.8 & 1.71 & 0.9 & 2.2 & 0.7 & 2.2 & 0.8 \\
\hline DVH & 2.1 & 0.9 & 2.2 & 0.8 & 1.5 & 0.9 & 2.06 & 0.9 & 1.9 & 0.7 & 1.4 & 1.0 \\
\hline DV & 1.8 & 0.8 & 1.0 & 1.1 & 1.6 & 1.1 & 1.77 & 1.1 & 1.2 & 0.4 & 1.8 & 0.7 \\
\hline $\mathrm{DE}$ & 0.4 & 0.9 & 0.0 & 0.3 & 0.4 & 0.6 & 0.08 & 0.4 & 2.0 & 0.9 & 0.2 & 0.5 \\
\hline FL & 1.2 & 1.1 & 0.3 & 0.6 & 1.9 & 1.5 & 0.85 & 1.2 & 0.7 & 0.8 & 0.7 & 0.8 \\
\hline HUM & 1.7 & 1.0 & 0.7 & 0.9 & 1.9 & 0.6 & 1.42 & 0.7 & 1.4 & 0.7 & 1.3 & 0.7 \\
\hline XSP & 4.7 & 2.0 & 3.1 & 1.7 & 6.3 & 2.0 & 5.96 & 2.7 & 5.5 & 2.5 & 4.5 & 1.8 \\
\hline NSP & 78 & & 65 & & 51 & & 68 & & 60 & & 70 & \\
\hline NTR & 367 & & 429 & & 200 & & 397 & & 284 & & 323 & \\
\hline SDI & $32.6 *$ & & 37.1 & & $19.3 * *$ & & 41.7 & & 30.7 & & 34.8 & \\
\hline
\end{tabular}

${ }^{*} \mathrm{~N}=47$.

${ }^{* *} \mathrm{~N}=44$.

Table IV summarizes the means of all the habitat variables in the different forest types and traplines. In general, primary forests tend to possess higher trees than do secondaries, with a high canopy and 
a more developed emergent connection. A well developed midstory, as measured by the connectedness at that stratum, is a characteristic of secondary forests. They also have a higher density of woody trees per unit area than primary forests because of the presence of a large number of trees with small basal areas. Although tree species richness tend to be higher in secondary forests, the average number of species per trapping station does not appear to differ between primary and secondary forests.

Correlation analyses between community parameters and habitat variables, lumped together across all traplines, indicate that there were no significant correlations between any of the habitat variables and the Shannon-Wiener index, or between these variables and species diversity as measured by the WH index. The number of species (s) showed a negative association with volume at the herbaceous stratum DVH $(r=0.17$, $p<0.05$ ), and a positive one with volume of midstory vegetation DVM $(r=0.17, p<0.05)$. These two habitat variables are probably not independent and may be measuring the same relationship. A negative association was found between herbaceous cover (HC) and both number of individuals (NI) and the weighted diversity index (WH) (respectively, $\mathrm{r}=0.57, \mathrm{p}<0.007 ; \mathrm{r}=0.52, \mathrm{p}<0.01)$. The total number of individuals was also positively associated with average height of trees $(r=0.41, p<0.05)$.

Shannon-Wiener Index

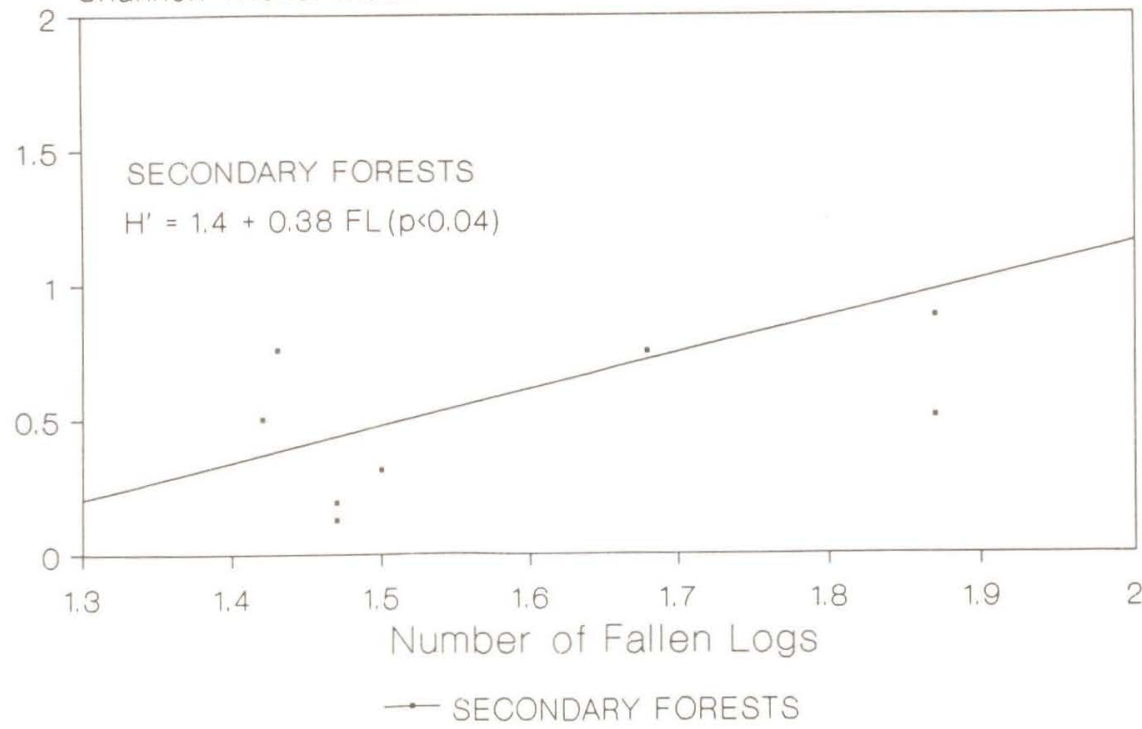

FIG. 7. Plot of $\mathrm{H}^{\prime}$ against $\mathrm{FL}$ for secondary forests, with each individual data point representing a forest trapline.

The second type of analysis investigated the effect of the habitat variables on the variation of $\mathrm{H}, \mathrm{WH}, \mathrm{S}$, and $\mathrm{NI}$, but this time primary and secondary forests were considered as separate data sets. Figure 7 
illustrates how the analysis of both primary and secondary forests together can be misleading: the regression between the number of fallen logs and $\mathrm{H}^{\prime}$ is non-significant when all sites are taken together. However, among secondary forest traplines, species diversity is significantly and positively associated with fallen logs. In contrast, the species diversity of primary forest traplines is not significantly associated with fallen logs.
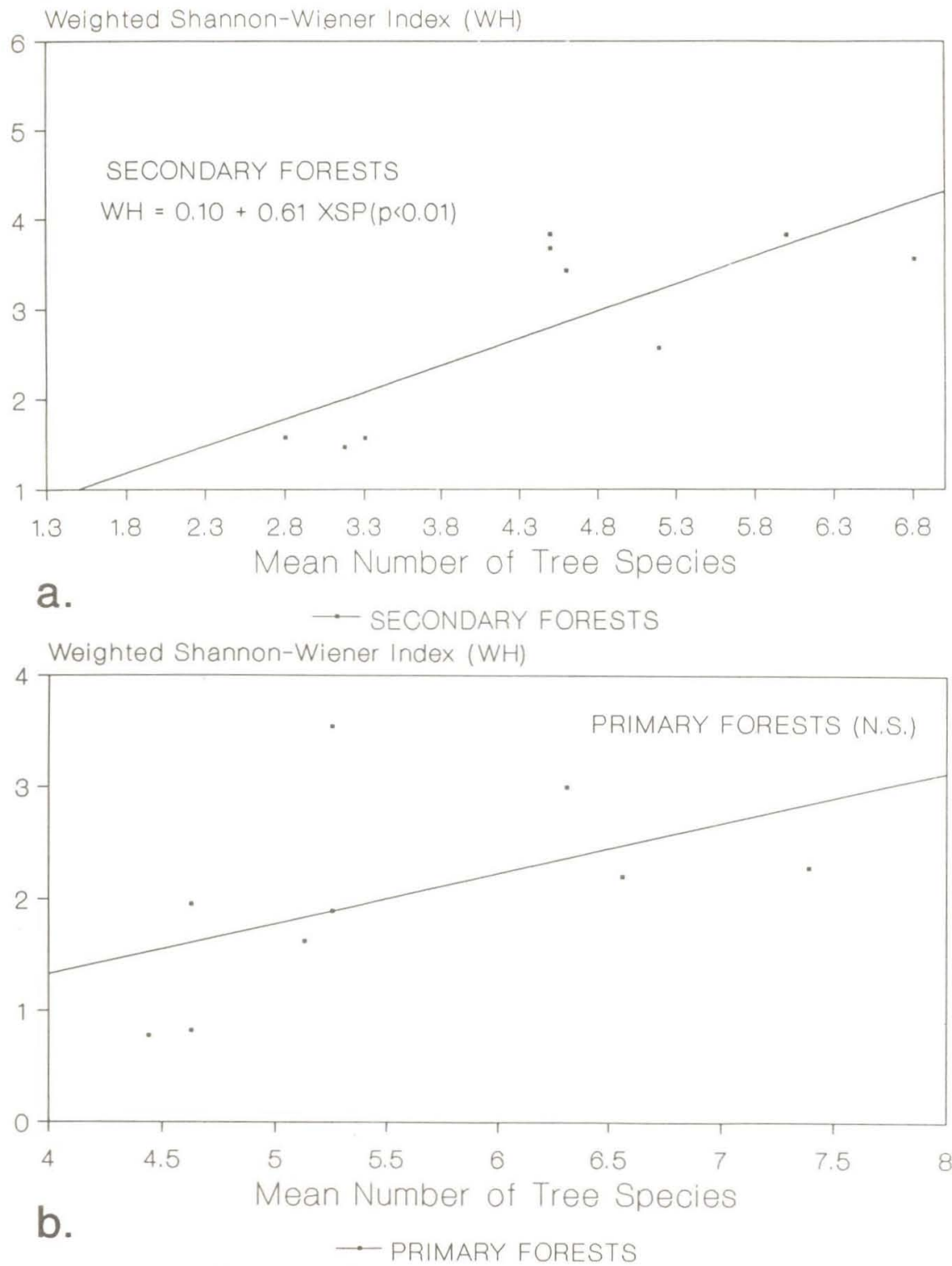

FIG. 8. Plots of WH against XSP, with individual data points representing forest traplines. 
Vol. 6(3), 1989

FIG. 8.a. shows the relationship for secondary forests, and FIG. 8.b. for primary forests only.
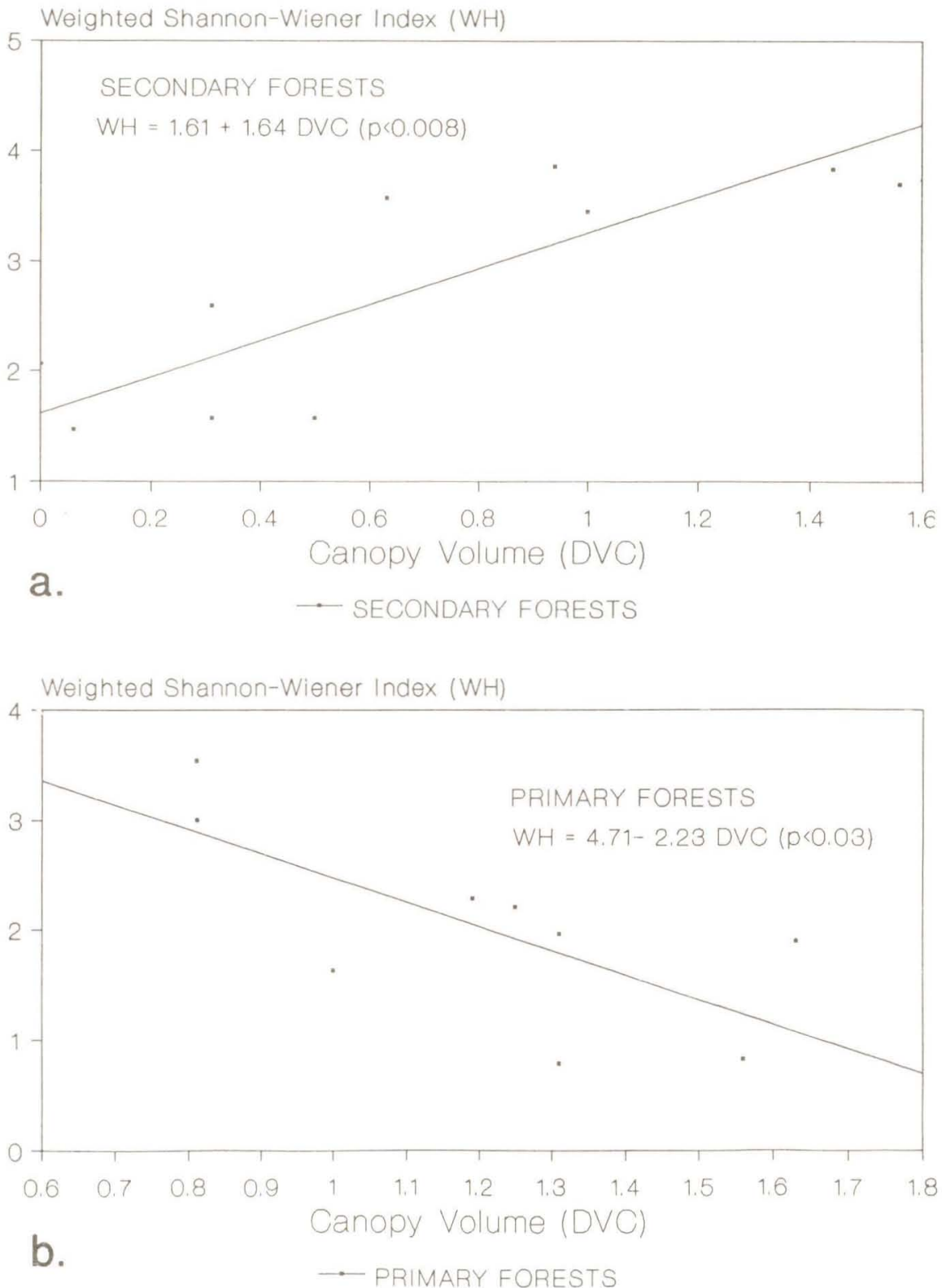

FIG. 9. Plots of WH against DVC, with each individual data point representing a forest trapline. FIG. $9 \mathrm{a}_{\mathrm{a}}$ shows the regression for secondary forests, and $9 \mathrm{~b}$. for primary forests. Note the opposite trends in WH between primary and secondary forests. 
Revta bras. Zool.

Therefore, the importance of specific habitat variables varies between primary and secondary forests. In figure 8, the plot i of WH against mean number of plant species (XSP) shows that even though both primary and secondary forests' $\mathrm{WH}$ indices tend to increase with
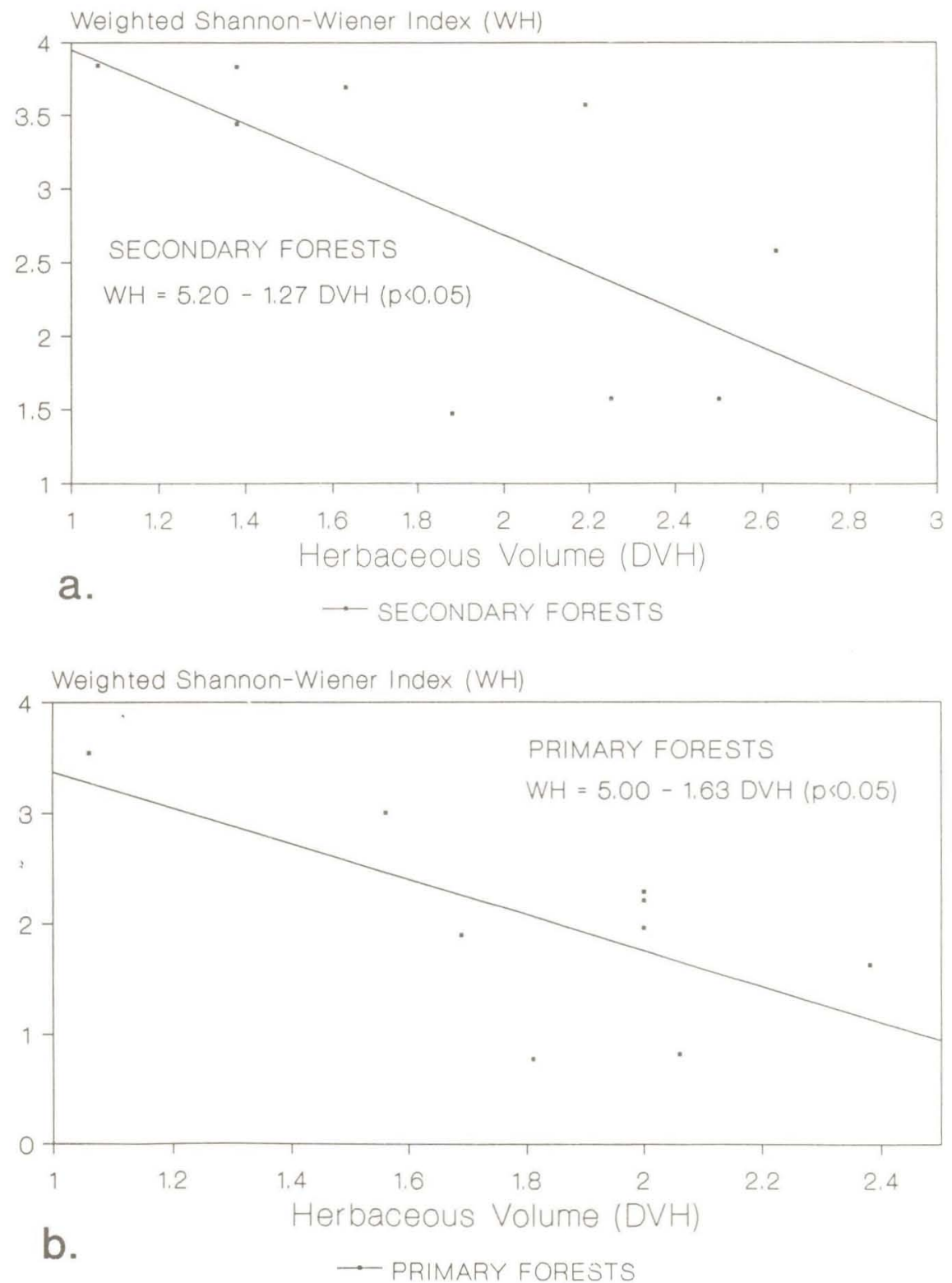

FIG.10. Plots of WH against DVH, with regressions for secondary $\left(10_{0} \mathrm{a}_{0}\right)$ and primary forests (10.b.) shown separately. 
the mean number of plant species present in the habitat, the regression for primary forests are not significant. The plot of WH against canopy volume (DVC) yields regressions with slopes of different signs for primary and secondary sites (Figure 9) The differential response of diversity of primary and secondary forests was not found, however, for all habitat variables. The weighted diversity index (WH) for both primary and secondary forests tend to decrease with the in herbaceous volume (DVH), both yielding significant regressions (Figure 10).

Species diversity, as measured by the Shannon-Wiener index $H^{\prime}$, appears to increase in secondary forests with higher trees and canopies ( $\mathrm{HT}, \mathrm{OH})$, with well developed connections in mid- and upper-stories (CXM, CXC). Diversity is also higher in well shaded areas (CC, DVC, DVM), and in trap stations close to fallen logs (FL). H' was also found to decrease with the amount herbaceous cover present (HH, DVH). The same general trends were obtained for species diversity as measured by $\mathrm{WH}$, but which also demonstrated to increase in areas with high vine density (DV). Diversity of primary forests, on the other hand, appears insensitive to most habitat variables measured, only a few of which were found to be correlated (Table V).

TABLE V. Summary of correlation analyses, showing habitat variables with significant correlation coefficients with Shannon-Wiener ( $\left.\mathrm{H}^{\prime}\right)$ and Weighted Shannon-Wiener (WH) diversity indices, with total number of individuals captured (NI), and number of species (S) $\left(^{*}=\mathrm{p}<0.05 ;{ }^{* *}=\mathrm{p}<0.01 ;{ }^{* * *}=\mathrm{p}<0.0001\right)$.

\begin{tabular}{|c|c|c|c|c|}
\hline \multirow[b]{3}{*}{ VARIABLE } & \multicolumn{2}{|c|}{ Secondary } & \multicolumn{2}{|c|}{ Primary } \\
\hline & $\mathrm{H}$ & WH & $\mathrm{H}$ & WH \\
\hline & r $\quad \mathrm{p}$ & r $\quad \mathrm{p}$ & $\mathrm{r}$ & $\mathbf{r}$ \\
\hline HT & $0.72^{*}$ & $0.85^{* *}$ & & \\
\hline $\mathrm{OH}$ & $0.89^{* *}$ & $0.92 * *$ & & \\
\hline $\mathrm{HH}$ & $-0.76^{*}$ & & & \\
\hline $\mathrm{CXC}$ & $0.90^{* *}$ & $0.69^{*}$ & & \\
\hline $\mathrm{CXM}$ & $0.95^{* * *}$ & $0.88 * *$ & & \\
\hline $\mathrm{CC}$ & $0.93^{* *}$ & $0.95^{* * *}$ & & $-0.68^{*}$ \\
\hline $\mathrm{HC}$ & & & & $-0.83^{* *}$ \\
\hline DVC & $0.88^{* *}$ & $0.73^{*}$ & & $-0.74 *$ \\
\hline DVM & $0.88 * *$ & $0.88^{* *}$ & & \\
\hline DVH & $-0.82^{* *}$ & & & $-0.69^{*}$ \\
\hline DV & & $0.78^{* *}$ & & \\
\hline FL & $0.68^{*}$ & $0.78^{* *}$ & & \\
\hline X SP & & $0.79 * *$ & & \\
\hline HUM & & & $-0.62^{*}$ & \\
\hline
\end{tabular}


TABLE V. continued

\begin{tabular}{|c|c|c|c|c|c|}
\hline \multirow[b]{3}{*}{ VARIABLE } & \multicolumn{2}{|c|}{ Secondary } & \multicolumn{3}{|c|}{ Primary } \\
\hline & $S$ & NI & \multicolumn{2}{|c|}{$\mathrm{S}$} & NI \\
\hline & r $\quad \mathrm{p}$ & r $\quad \mathrm{p}$ & $\mathrm{r}$ & $\mathrm{p}$ & $\mathrm{p}$ \\
\hline HT & $0.70^{*}$ & $0.86^{* *}$ & & & \\
\hline $\mathrm{OH}$ & $0.84^{* *}$ & $0.96^{* * *}$ & & & \\
\hline $\mathrm{HH}$ & $-0.80^{* *}$ & & & & \\
\hline $\mathrm{CXC}$ & $0.90^{* *}$ & $0.79^{* *}$ & & & \\
\hline CXM & $0.93^{* *}$ & $0.87^{* *}$ & & & \\
\hline $\mathrm{CC}$ & $0.85^{* *}$ & $0.95^{* * *}$ & & & $-0.68^{*}$ \\
\hline $\mathrm{HC}$ & & & & & $-0.84 * *$ \\
\hline DVC & $0.83^{* *}$ & $0.81^{* *}$ & & & $-0.70^{*}$ \\
\hline DVM & $0.88 * *$ & $0.84^{* *}$ & & & \\
\hline DVH & $-0.81^{* *}$ & $-0.68^{*}$ & & & $-0.66^{*}$ \\
\hline FL & & $0.75^{*}$ & & & $0.80^{* *}$ \\
\hline XSP & & $0.74^{*}$ & & & \\
\hline
\end{tabular}

The above relationship also held the same trend for the component variables of the diversity indices, i.e., number of species and number of individuals (Table V). Species richness (S) was associated with all

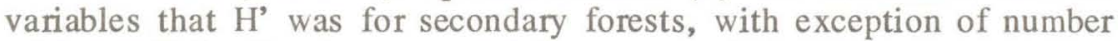
of logs (FL). Total number of individuals (NI) of secondaries was associated with all habitat variables that $\mathrm{WH}$ was plus herbaceous volume (DVH). In contrast, the number of species (S) in primary forests was not associated with any of the habitat variables measured. Number of small mammal individuals of primary sommunities (NI) was significantly associated with all variables that WH was plus number of fallen $10 \mathrm{gs}$ (FL).

We investigated the possible association between area size and the community parameters total number of species per unit area (S), number of individuals per unit area (NI) and species diversity per unit area, as measured by $\mathrm{H}^{\prime}$ and $\mathrm{WH}$. There were three main category sizes, each represented by two forests, one primary and another secondary: small (60 and 80 ha), medium (860 ha) and large (35,983 ha). In all cases loge (area size) provided a better fit. There is no significant association between area size and any of the community variables if primary and secondary forests are lumped together. However, area size yielded significant correlations with $\mathrm{H}^{\prime}, \mathrm{WH}, \mathrm{S}$ and NI secondary forests were examined separetily (respectively, $r=0.92, \quad p<0.004 ; \quad r=0.84$, $\mathrm{p}<0.003 ; \mathrm{r}=0.92, \mathrm{p}<0.004 ; \mathrm{r}=0.84, \mathrm{p}<0.003)$. 
Vol. 6(3), 1989

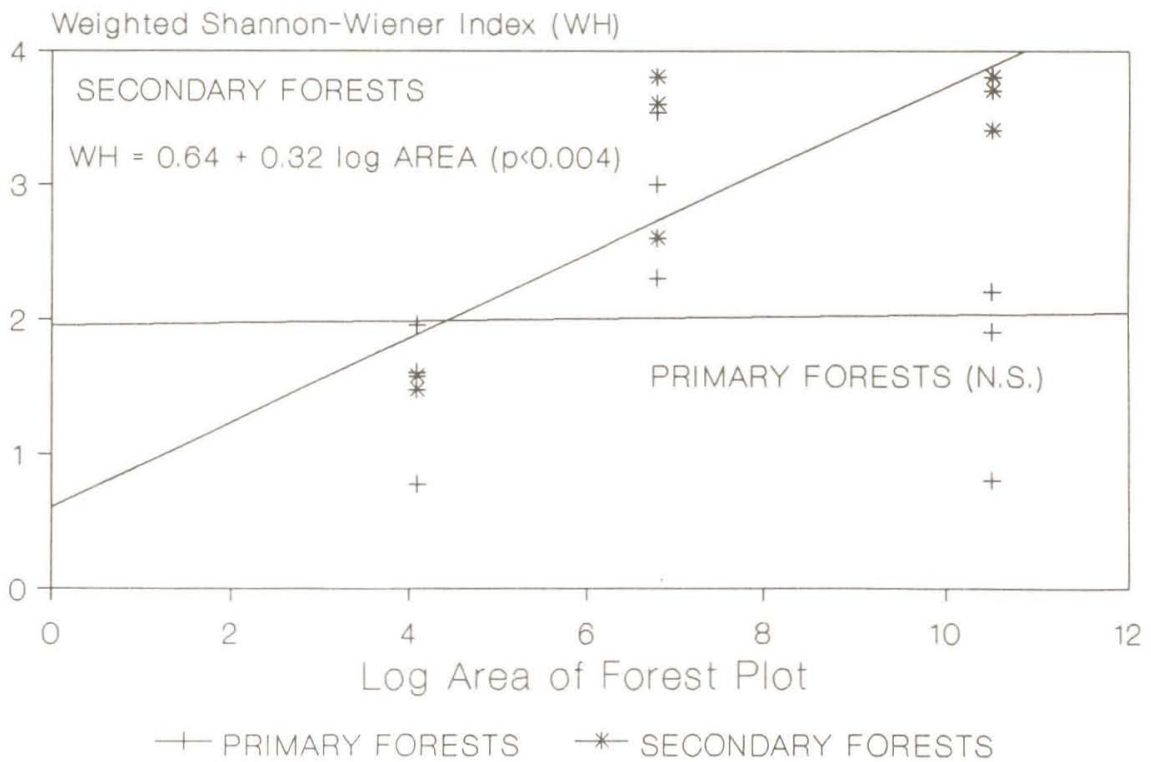

FIG.11. Plots of WH and log area size for secondary and primary forests. Note that the regression is significant for secondary forests, while the one for primary forests is not. WH of primary forests do tend to increase from the small to the medium size category, but no change can be noticed between medium and large size forest traplines.

On the other hand, no significant trends were observed for primary forests alone. Figure 11 illustrates the relationship found for the separate analysis between primary and secondary forests. Primary forests species diversity (as measured by WH) does tend to increase with area from the small size to the medium size category (Table II), but species diversity of large primary traplines dropped to levels comparable with the ones obtained for the smaller forests plots.

Based on all of the above results, we then eliminated those independent habitat variables that were either intercorrelated or that on their own did not explain any significant amount of variation in the mammal species diversity variables. In addition, those habitat variables that were significantly associated with area size were also dropped. It was therefore possible to construct multivariate models that included both the effect of area size and habitat characteristics. 
Vol. 6(3), 1989

TABLE VI. Multiple regressions of Shannon-Wiener $(\mathrm{H})$ and Weighted Shannon-Wiener (WH) indices, and its components, against habitat variables. $\mathrm{S}=$ number of species of small mammals; NI=total number of individuals of small mammals trapped at each transect line.

\section{PREDICTOR VARIABLES}

IN MODEL

\begin{tabular}{ll}
\cline { 2 - 2 } & Secondary Forests \\
\hline $\mathrm{r}^{2}$ & $\mathrm{p}<$ \\
\hline
\end{tabular}

Dependent Variable $=\mathrm{H}$

F L

A

0.39

0.04

0.84

0.0004

F L, A

0.92

0.0002

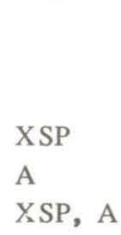

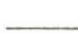

Dependent Variable $=\mathrm{WH}$

\begin{tabular}{ll}
\hline 0.57 & 0.01 \\
0.71 & 0.003 \\
0.97 & 0.0001 \\
& \\
\hline \multicolumn{2}{c}{ Dependent Variable $=S$} \\
\hline
\end{tabular}

No Habitat predictor

variables recognized

A

$\begin{array}{ll}0.84 & 0.0004\end{array}$

Dependent $\mathrm{V}$ ariable $=\mathrm{NI}$

MEANSP

A

$\begin{array}{ll}0,49 & 0.02 \\ 0.72 & 0.003 \\ 0.91 & 0.0003\end{array}$

MEANSP, A

0.91

0.0003

\begin{tabular}{ll} 
& Primary Forests \\
\hline $\mathrm{r}^{2}$ & $\mathrm{p}^{<}$ \\
\hline \multicolumn{3}{c}{ Dependent Variable $=\mathrm{H}$} \\
\hline
\end{tabular}

No Habitat predictor variables recognized A 
Vol. 6(3), 1989

Table VI continued

DVH, DVC

A

\begin{tabular}{ll}
\hline \multicolumn{2}{c}{ Dependent Variable $=\mathrm{WH}$} \\
\hline 0.65 & 0.01 \\
& $\mathrm{n}_{\text {.S. }}$ \\
\multicolumn{3}{l}{ Dependent Variable $=\mathrm{S}$} \\
\hline
\end{tabular}

No Habitat predictor variables recognized

A

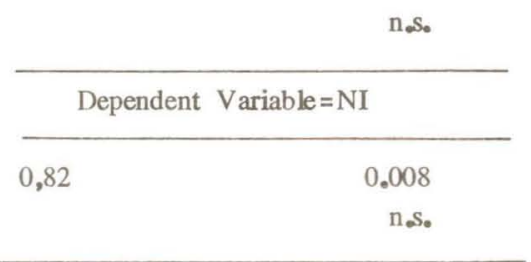

TABLE VII. Multiple correlation coefficients for habitat and area variables in regression models of species diversity for secondary forests. The \% column refers to percentage of variance attributable to area size, and is equal to the following ratio:

(Area $r^{2}$-Habitat $r^{2}$ )/Overall $r^{2}$.

DEPENDENT

VARIABLE

$\mathrm{H}$

WH
Secondary Forests

\begin{tabular}{ccccc}
\hline Overall $r^{2}$ & Habitat $r^{2}$ & Area $r^{2}$ & Area-Habitat & $\%$ \\
\hline 0.92 & 0.08 & 0.53 & 0.45 & 48.9 \\
0.97 & 0.26 & 0.40 & 0.14 & 14.4
\end{tabular}

The best models for H' at secondary forests were obtained by using number of fallen $\operatorname{logs}$ (FL) and area size, which was able to explain $92 \%$ of the variation in species diversity (Table VI). For WH, the mean number of plant species in trapping station (XSP) and area size together explained $97 \%$ of the variation. Area size alone explained $84 \%$ of the variation in species richnness, even though connectedness at the midstory (CXM), a variable correlated with size, accounted for the approximately the same amount of variation in the number of species $(86 \%)$. No multivariate model for the total number of individuals (NI) generated with the above method was able to obtain a significantly better fit than overstory height (for $\mathrm{OH}$ alone: $\mathrm{r}^{2}=.92, \mathrm{p}<0.0001$; for XSP and 
area: $\left.r^{2}=.91, p<0.0003\right)$. Therefore, for both species richness and number of individuals, theanalysis did not proceed further. On the other hand, the multivariate regression analysis for species diversity of secondary forests can be further separeted into its components, as shown in Table VII. Shannon-Wiener species diversity is better explained by both the habitat variable used in the model and area size. However, arae size appears to contribute to approximately $48.9 \%$ of the variation in $\mathrm{H}^{\prime}$ in the complete model, or a litlle more than does the habitat structure variable. In the $\mathrm{WH}$ model, on the other hand, area appears to contribute less than the habitat variable (XSP) in the variation of the dependent variable (14.4\%).

For primary forests area size did not function as a predictor in any of the models (Table VII). No multivariate regression model that included area size was better able to explain variation in $\mathrm{H}^{\prime}, \mathrm{WH}$ and $S$ than either of the previous habitat structure variables that were significantly correlated with species diversity. There was, however, a model for NI that included more than one non-correlated habitat structure variable that provided a better fit to the data. This included number of fallen logs (FL) and herbaceous cover (HC), the former with a positive parameter and the later with a negative one.

\section{DISCUSSION}

This study indicated that marsupials predominate both in terms of number individuals and in biomass in the small mammal forest communities of the Brazilian Atlantic forest region. Rodent species richness was comparable to that of marsupials in the larger plots, while some rodent species were quite common in the medium sized plots. Previous studies in neotropical forests have yielded contrasting results: LAEMMERT et al. (1946) in the northem part of the Atlantic forest, and EMMONS (1984) and MALCOLM (1987) in the Amazon region, have found rodents to outnumber marsupials in species diversity and abundance. STALLINGS (1988), using the same trapline methods of this study in the Rio Doce State Park, found that marsupials outnumbered rodents. No definite explanation is yet possible for these different results, although marsupial overabundance may be related to the present-day high frequency of occurrence of second growth habitat in the Atlantic forest region. Second growth has been shown to be more productive in terms to the food resources used by marsupials (CHARLESDOMINIQUE et al., 1981).

This study has shown that primary forests tend to have lower small mammal species diversity. Taking $\mathrm{H}^{\prime}$ as a measure of species diversity, no primary forest plot, regardless of size, was more diverse than any 
of the secondary sites. The lowest species richness and diversity was recorded for a site which, in spite of its large size, was mostly primary in nature. The results also indicated that higher species richness and diversity are found in secondary forest that are of large size. I should stress that these are relatively older-grow th secondary forests, averaging about than 20 years old. CHARLES-DOMINIQUE et al. (1981) found that the marsupial part of a community in French Guyana is much more diverse and abundant in secondary growth. ISABIRIE-BASUTA and KASENENE (1987) also found rodent species diversity and abundances to be higher in selectively felled forests, when compared with relatively undisturbed primary vegetation. Recent studies in younger forests (less than 5-8 years) indicate that species richness and diversity also decrease in very early growth forests (FONSECA et al., 1987). These forests are characterized by even-aged tree stands, which tend to be structurally homogeneous.

These results are in accord with other studies of diversity and of plant community succession. They all have indicated that climax communities are found to be less diverse than some younger stage, provided the nature of the disturbance is not of extreme frequency or intensity (CONNELL, 1978; SOUZA, 1984; BROKAW, 1985; GLITZENSTEIN et al., 1986). As HORN (1974) has stated,

"Only one pattern of diversity in succession should be nearly universal. In a succession that is not subject to extensive and chronic disturbance, the diversity of the climax must be lower than that of some preceding stage." (page 30).

The habitat variables that were associated with significant amounts of variation in the small mammal community variables indicate that for both primary and secondary forests species richness and diversity will be higher in habitats with a well developed midstory. This is reflected by those variables related to midstory volume and vine density. Species richness and also the total number of individuals in he community are negatively associated with presence of well developed herbaceous vegetation. Moreover, population sizes are also larger in forests with higher trees (but excluding emergents). While well developed herbaceous vegetation is usually associated with second growth, higher trees are not. However, on station to station basis, average height and volume of herbaceous vegetation of secondary forests are not necessarily higher than in primary ones (see Table IV). Even though herbaceous cover in very young forests can be-attributable to lack of heavy tree cover, a well developed midstory, characteristic of many older-growth secondary forests, in much more efficient in buffering light than canopies dominated by a few emergents, a characteristic of Atlantic region climax primary forests. These observations thus lend further support to the contention that small mammal communities will be richer in mid- to older stages of secondary growth than either very young or very old forest 
communities.

The importance of mid-growth as a determinant of small mammal diversity is also evident if we examine primary forest regression models separately. While $\mathrm{H}^{\prime}$ and number of species in primary forests do not relate strongly to most any habitat variables measured, the exceptions are notwithstanding meaningful. The habitat variables included in regression model for primary forests indicate that diversity and number of individuals increase with the reduction in volume of vegetation at the canopy strata and increase with the amount of fallen logs. Therefore, communities of secondary forests tend to be more diverse than climax forests, while traplines within primary forests crossing gaps or areas with some form of disturbance also yield higher species diversity.

Diversity and richness among secondary forests are usually associated with vegetation possessing several characteristics, such as well developed midstories, taller trees, and as importantly, the number of fallen logs. Number of individuals in the primary communities was also positively correlated with this last variable. Fallen logs potentially constitute an important resource for terrestrial species. MALCOLM (pers. comm.) found Proechimys in central Amazonia highly associated with fallen logs, in which they look for refuge and use extensively for locomotion (see also FONSECA, 1988). Moreover, MILES et al. (1981) also found Proechimys using fallen logs as substrate for locomotion and taking refuge in hollow logs. The behavioral response upon release of most of the small mammal species in this study indicated that gaps under fallen trunks are a preferred location for an escaping individual. But since knowledge of the natural history of these species is still superficial, the exact role of fallen logs remains an open question.

Several studies have shown that species compositions and relative abundances of small mammal communities can be partially explained by habitat structure and heterogeneity (ROSENZWEIG \& WINAKUR, 1969; M'CLOSKEY, 1976; DUESER \& SHUGART, 1978; AUGUST, 1983, 1984; LACHER et al., in press; LACHER \& ALHO, in press). Bird community studies have also revealed these correlations (JOHNSON, 1975; JAMES \& WAMER, 1982; LYNCH \& WHIGHAM, 1984). Other studies have focussed on area size as a determinant of mammalian insular species richness (DUESER \& BROWN, 1980; LOMOLINO, 1984; MALCOLM, 1987). A problem for both approaches is that several habitat variables covary with area size, and it is often difficult to separate the "pure" or dynamic effects of area sensu MacARTHUR \& WILSON (1967) from the habitat structure question. ZIMMERMAN \& BIERREGAARD (1986) using tree frog data from Amazon forest fragments, WEAVER \& KELLMAN (1981) with birds, and WESTMAN (1983) plant associations, all have empirically warned against the unqualified use of island biogeographical derivations. Some studies have been successful in separating, or at least controlling for area size and habitat structure (BUCKLEY, 1982; 1985; BOECKLEN, 1986). In his mangrove island experiments with arthropod communities, SIMBER LOFF (1976) was able to identify variables related to habitat structural diversity 
that were able to explain some of the variation in the number of species, and that were independent of island size.

In this study I separated the effects on small mammal diversity of a few habitat variables from those of forest fragment size. Some of the best models for species diversity of secondary forests included both the effect of "area size" alone and one or two habitat variables non-correlated with size. The effects of area and habitat for both species diversity indices were identified and their relative importance for the determination of species diversity established. Area was responsible for a little over half of the variation in $\mathrm{H}^{\prime}$ in secondary forests, with habitat being responsible for the remaining.

There are several possible ways in which small mammal diversity would be increased in secondary forests. Unfortunately, a many number of habitat variables were not used in regression models due to colinearity problems. Thus, the interpretation of the underlying mechanisms by which the specific habitat variables used in regression models affect variation in small mammal community patterns was not totally clear. As it has been demonstrated in another circumstance (WEAVER \& KELLMAN, 1981), differential rates of extinction can sometimes be directly linked to final stages of sucession, more so than area size, with pioneer species being unable to persist in mature forests. Forests that provide niche space in their intermediate stages of succession for both pioneer and secondary invading species are much better able to maintain a more diverse fauna. Mid-stage second growth communities would be then characterized by species with higher evenness within a particular guild than structurally simple mature forest communities dominated by a few species. Furthermore, it is suspected that very few small mammal species of the Brazilian Atlantic region, and perhaps elsewhere in the tropics, depend on climax forests. Corroborating this hypothesis, with the exception of one species represented by one individual, all species of the primary communities examined here were also recorded elsewhere in secondaries. Moreover, seven species could only be found in secondary settings, a further indication that mid-level succession stages are better able to maintain a larger diversity at the local level. ISABYRIE-BASUTA \& KASENENE (1987) determined that all but one species present in mature African forests were also represented in disturbed forests. Similarly, no vertebrate species of the Western Cascades of the United States has been shown to dwell exclusively on mature forests (HARRIS, 1984), although some species, such as the spotted owl and Arborimus, may be more dependent on old forest stands (EISENBERG, pers. comm.).

An alternative explanation to the results obtained here wouid be that the arboreal trapping methods were not able to adequately represent a possible unique primary forest fauna that could inhabit higher vegetation strata, or that arboreal species are more easily trapped in secondary forests because of their lower canopy. This does not seem to be the case. STALLINGS (1988), using arboreal plataforms, has trapped extensively in higher strata of two forests of the Rio Doce Park. His 
sample did not yield any additional species than the ones reported for this study, even though some of the more arboreal marsupials (Marmosa cinerea and Caluromys philander) were overly represented in relation to ground trapping. An exception may be the arboreal spiny rat Echymys sp., which according to MILES et al. (1981), is never observed on the ground. However, the species was only represented in this study by one individual in one forest plot, and therefore did not have a major effect in altering the results of this analysis.

Species diversity per unit area of primary forests, on the other hand, does not seem to be affected by area size. Why is it that species diversity of secondary forests respond to area size and primary forests do not? Vertical packing of species has been originally described for avian communities (MacARTHUR, 1957). Since 11 out of the 19 small mammal species demonstrate variable degrees of climbing ability (see FONSECA, 1988), the addition of a well developed 3-dimensional environment can similarly potentially provide additional and broader niche space. A growth in species richness and diversity of secondary forests with a corresponding increase in area size might conceivably be achieved by:

1. The growth in the individual sizes of species populations, possible because of the increase in the width of the individual niches of 3-dimensional environments, and/or by decreasing extinction rates in larger areas.

2. The increase in alpha-diversity, represented by midstory structural components such as vines and canopies of mid-story secondgrowth trees.

3. The increase in beta-diversity.

The first factor certainly lowers the probabilities of local extinctions from particular communities. The second factor increases habitat heterogeneity both in relation to primary forest structure and also by, as gaps other openings tend to differ from one another (SOUZA, 1984), the increase in the number of distinct habitats that become available. This line of reasoning links both the habitat structure/diversity theory of WILLIAMS (1964) and the MacARTHUR \& WILSON extinction/ colonization dynamic model, without the need to invalidate neither one of them. Species diversity of primary forests communities, on the other hand, due to their relatively larger homogeneity per unit area and the absence of developed midstory, are less capable of locally responding to changes in area size. Probably very large changes in area size (or sampling effort) would be necessary to notice these influences.

Although productivity of small mammal resources was not measured, it is felt that it can also exert a certain degree of influence on community 
parameters. Second growth vegetation can possibly be more productive for marsupials (see CHARLES-DOMINIQUE, 1983), as well as for rodents. If this is the case, one might expect that the consequent response to area size would be much more noticeable in secondary than in primary forests. Some primary productivity measures have been found to increase species diversity in plant communities (HORN, 1974). Recently, HUNTLY \& INOUYE (1987) suggested that, for a relatively simple small mammal community of central Minnesota, measures of primary productivity, such as nitrogen content, may play a role in increasing species diversity and abundances. Similarly CHARLES-DOMINIQUE et al. (1981) have implicated the low diversity and biomasses of didelphid marsupials at French Guyanan primary forests as the result of lower productivity, relative to secondary vegetation. Apparently, the frugivore portion of the marsupial diet is overly represented by items characteristic of pioneer plant species.

\section{CONSERVATION AND MANAGEMENT IMPLCATIONS}

The traditional view of tropical forest animal and plant communities is that of the inexorable march towards a stable climax characterized by the highest possible assemblage of tightly packed species. The notion that disturbance regimes that are higher in magnitude than presumed "historical" ones always tend towards a reduction in diversity (DENSLOW, 1985), especially in the tropics, is still quite common in the literature.

Even though it is not wise to extrapolate the results of this study, which focused on only one guild, to other mammals of the tropical region, it is possible to say that small mammal species richness and diversity of the forests examinea here are at their highest in mid-growth secondary forests. The role of edge effects on temperate communities (WEAVER \& KELLMAN, 1981) and the suggestion that some level of disturbance is necessary for maintaining high species diversity, even in tropical communities (CONNELL, 1978, KARR, 1982), is now receiving increasing support from field data. However, LOVEJOY et al. (1986) have found that the bird fauna of the edges of small isolated reserved in the Amazon basin tend towards a decrease in species diversity and relative abundances, while MALCOLM (1987) did not find any conclusive evidence for the small mammal communities of these same reserves. Furthermore, some primate species may not survive if the mode of habitat alteration is such as to drastically reduce important food resources (JOHNS \& SKORUPA, 1987) although moderately disturbed forests are nonetheless capable of maintaining most rain forest primates. These contrasting results should make us careful about generalizations, specially between different guilds and taxa.

The findings of this study are also pertinent to the decade long SLOSS (Single Large or Several Small Reserves) debate on reserve 
planning (DIAMOND, 1975; SIMBERLOFF \& ABELE, 1976; SIMBERLOFF, 1982; QUINN \& HASTINGS, 1987). I have determined that all four forest patches of small and medium size $(60,80$ and 860 ha) together yielded 11 species, while the single large forest of secondary nature alone supported 14 small mammal species (Table I). Therefore, the evidence with small mammals supports the contention that larger patches do support higher species diversity per unit area than a collection of smaller reserves. I should stress that the argument for multiple reserves is usually conducted with the idea that the added area of these reserves is similar in size to that of the large unit being compared, which is clearly not the case here. However, since all reserves were sampled with the same trapping effort and over sampling areas of the same size (6 ha), the comparison is still meaningful. We have to consider that smaller reserves together turned out 11 species using four sets of traplines (24 ha), in contrast with 14 species in a single set (6 ha) in the large reserve. Nevertheless, it is necessary to realize that the habitat structure of a reserve is also crucial, since the large primary forest of this study proved one of the most species poor communities studied. Thus, even though forests of larger sizes usually support more resilient communities, the pure application of island biogeography to conservation and research design in the tropics is not advisable. Habitat evaluation and studies of the life histories of individual species is of utmost importance if we are to establish sound planning methods.

\section{ACKNOWLEDGEMENTS}

First and foremost, I would like to thank John G. Robinson for his dedication to my work. His advice during planning, field work, analysis and writing of this paper were invaluable. John Eisenberg, Larry Harris, Nigel Smith, Melvin Sunquist, and Charles Woods provided support in the planning of this study and improvements in earlier drafts. This research also benefited from discussions with Thomas Lacher, Kent Redford, Russell Mittermeier and Michael Mares. Two other reviewers offered valuable suggestions, some of them adopted here.

Celio Valle encouraged the field work with his enthusiasm, vision, and eternal optimism. Several people helped during field work: Ludmilla A guiar, Ilmar Bastos, Sonia Rigueira, Carlos Alberto Pinto, Ederson Machado (sometimes), Silverio Machado, Ney Carne valli, Luiz Fernando Mello, Gisela Hermann, Jairo Vieira, Eduardo Veado, Eduardo Sabato, Luiz Paulo Pinto, and Maria Cristina Alves. My small mammal data from the Rio Doce Park was partially collected by Jody Stallings and his crew.

Mr. Feliciano Abdalla and Dr. Antonio Cupertino kindly allowed me to work on their farms and provided housing. "Santinho" let us stay in his house at the expense of family problems, and I am thankful 
to him. The State Forest Institute of Minas Gerais (IEF) provided me with accommodations and gasoline at the Rio Doce State Park. I am very grateful to the staff of the Park, especially Ademir Camara Lopes, Jose Lourenço Ladeira and Hermogenes Ferreira Neto. M. Carleton, K. Creighton, L. Emmons, G. Musser, P. Myers, and J. Patton generously identified the small mammal voucher specimens.

The World Wildlife Fund-US financed the most substantial part of the costs involved in this study. Additional financial support was provided by the Program for Studies in Tropical Conservation, of the University of Florida, and by the Research Council of the Federal University of Minas Gerais, Brazil. The National Research Council of Brazil (CNPq) awarded me with a doctoral fellowship.

\section{REFERENCES}

A LHO, C. J. R. 1981. Small mammal populations of Brazilian Cerrado: the dependence of abundance and diversity on habitat complexity. Revta bras. Biol. 41(1):223-230.

ALHO, C. J. R., L. A. PEREIRA, \& A.C. PAULA. 1986. Patterns of habitat utilization by small mammal populations in cerrado biome of central Brazil. Mammalia 50(4):447-460.

ALMEIDA, F.A \& M. Z. P. ROCHA. 1977. Estabelecimento de áreas mínimas de preservação dos diversos ecosistemas terrestres do Brasil. In: Encontro Nacional sobre Conservação de Fauna e Recursos Faunísticos, organized by IBDF and Academia Brasileira de Ciências, Brasflia, DF.

ALONSO, M. T. A. 1977. Vegetaçäo. Regiāo Sudeste. In: Geografia do Brasil. Instituto Brasileiro de Geografia e Estatística, IBGE, Rio de Janeiro, RJ.

AUGUST, P. V. 1983. The role of habitat complexity and heterogeneity in structuring tropical mammal communities. Eoology 64:1495-1513.

AUGUST. P.V. 1984. Population ecology of small mammals in the Llanos of Venezuela. In: R. E. MARTIN \& B. R. CHAPMAN (eds.), Contributions in Mammalogy in Honor of Robert L. Packard. Texas Tech. University, Lubbock, Texas.

BOECKLEN, W. J. 1986. Effects of habitat heterogeneity on the species-area relationships of forest birds. J. Biogeogr. 13:59-68.

BOURLIERE, F. 1983. Species richness in tropical forest vertebrates. In G. MAURYLECHON, M. HADLEY \& T. YOUNES (eds.), The Significance of Species Diversity in Tropical Forest Ecosystems, Report of the meeting of the IUBS Working Group on Species Diversity/Decade of the Tropics Programme, Paris-France. 
BROKA W, N. V. L. 1985. Treefalls, Regrowth, and Community structure in tropical forests. In: S. T. A. PICKETT \& P. S. WHITE (eds.), The Ecology of natural Disturbance and Patch Dynamics. Academic Press, New York.

BUCKLEY, R. 1982. The habitat-unit model of island biogeography. J. Biogeogr. 9:339-344.

BUCKLEY, R. 1985. Distinguishing the effects of area and habitat type on island plant species richness by separating floristic elements and substrate types and controlling for island isolation. J. Biogeogr. 12:527-535.

CHARLES-DOMINIQUE, P. 1983. Ecology and social adaptations in didelphid marsupials: comparison with eutherians of similar ecology. In: J. F. EISENBERG \& D. G. KLEIMAN, Advances in the Study of Mammalian Behavior. Special Publication $N^{\circ} 7$, American Society of Mammalogists.

CHAR LES-DOMINIQUE, P. M. ATRAMENTOWICZ, M. CHARLES-DOMINIQUE, H. GERARD, A, HLADIK, C. M. HLADIK \& M. PREVOST. 1981. Les mammiferes frugivores arboricoles nocturnes d'une foret guyanaise: inter-relations plant-animaux. Rev. D'Ecologie, 35:341-435.

COIMBRA-FILHO, A. F. \& R. A. MITTERMEIER. 1977. Conservation of the Brazilian lion tamarins (Leontopithecus rosalia). In: Prince RAINIER of Monaco \& $\mathrm{G}_{\bullet} \mathrm{H}_{\text {. }}$ BOURNE (eds.), Primate Conservation. Academic Press, New York.

CONANT, F., P. ROGERS, M. BAUMGARDNER, C. McKELL, R. DASMANN \& P. REINING. 1983. Resource Inventory and Baseline Study for Developing Countries. American Association for the Advancement of Science, Washington, D. C. $539 \mathrm{pp}$.

CONNELL, J. H. 1978. Diversity in tropical rain forests and coral reefs. Science 199:1302-1310.

CONNELL, J. H. \& R. O. SLATYER. 1977. Mechanisms of sucession in natural communities and their role in community stability and organization. Am. Nat. 111:1119-1144.

DARLINGTON, P. J. 1957. Zoogeography: the Geographical Distribution of Animals. Wiley and Sons, London.

DAVIS, D. E. 1946. The annual cycle of plants, mosquitoes, birds and mammals in two Brazilian forests. Ecological Monographs 15:244-295.

DAVIS, D. E. 1947. Notes on the life histories of some Brazilian mammals. Bolm Mus, Nac, 76:1-8.

DELANY, M. J. 1986. Ecology of small rodents in Africa. Mammal Rev. 16(1):1-41. 
Vol. 6(3), 1989

DENSLOW, J. S. 1985. Disturbance-mediated coexistence of species, In : S. T. A. PICKETT \& P. S. WHITE (eds.), The Ecology of Natural Disturbance and Patch Dynamics. Academic Press, New York.

DIAMOND, J. M. 1975. The island dilema: lessons of modern biogeographical studies for the design of natural reserves, Biol. Conserv. $7: 129-146$.

DUESER, R. D. \& W. C. BROWN. 1980. Ecological correlates of insular rodent diversity. Ecology 61:50-56.

DUESER, R. D. \& J. H. PORTER. 1986. Habitat use by insular small mammals: relative effects of competition and habitat structure. Ecology 67(1):195-201.

DUESER, R. D. \& H. H. SHUGART. 1978. Microhabitats in a forest-floor small mammal fauna. Ecology 59(1):89-97.

EISENBERG, J. F. 1980. The density and biomass of tropical mammals, In: M. SOULE \& B. WILCOX (eds。), Conservation Biology: An Evolutionary-Ecological Perspective. Sinauer Press, Sunderland, Massachussets.

EITEN, G. 1974. An outline of the vegetation of South America. S ymp. Congr. Int. Primatol. Soc. 5 th, 529-545.

EMMONS, L. H. 1984. Geographical variation in densities and diversities of non-flying mammals in Amazonia. Biotropica 16(3):210-222.

EMMONS, L. H., A. GAUTIER-HION \& G. DUBOST. 1983. Community structure of the frugivorous-folivorous forest mammals of Gabon. J. Zool., Lond. 199:209-222.

FLEMING, T. H. 1971. Population ecology of three species of neotropical rodents. Misc. Publ. Mus, Zool. Univ. Michigan 143:1-77.

F LEMING, T. H. 1975a. The population ecology of two species of Costa Rican heteromyid rodents. Ecology $55: 493-510$.

FONSECA, G. A. B. 1983. The role of deforestation and private reserves in the conservation of the woolly spider monkey (Brachyteles arachnoides). Masters Thesis, University of Florida, Gainesville, Florida

FONSECA, G. A. B. 1985. The vanishing Brazilian Atlantic forest. Biol. Conserv. 34(1):17-34.

FONSECA, G. A. B. 1988. Patterns of small mammal species diversity in the Brazilian Atlantic Forest. Ph.D. Dissertation, University of Florida, Gainesville, Florida. 
FONSECA, G. A. B., L. F. B. MELLO \& G. HERRMANN. 1987. Inventariamento de mamíferos e estudo dos padrões de diversidade de espécies de pequenos mamíferos na EPDA de Peti-Minas Gerais.Report to CEMIG, Belo Horizonte, MG.

FONSECA, G. A. B. \& K . R. REDFORD. 1984. The mammals of IBGE's ecological reserve and an analysis of the role of gallery forests in increasing diversity. Revta bras. Biol., 44:517-523.

GLITZENSTEIN, J. S., PH. HARCOMBE \& D. R. STRENG. 1986. Disturbance, succession, and maintenance of species diversity in an east Texas forest. Ecol. Monogr. 56(3):243-258.

HAIR, J. D. 1982. measurement of ecological diversity. In: S. D. SCHEMNITZ (ed.), Wildlife Management Techiques Manual. The Wildlife Society, Washington, D. C.

HALLETT, J. G., M. A. O’CONNELL \& R. L. HONEYCUTT. 1983. Competition and habitat selection: test of a theory using small mammals. Oikos 40:175-181.

HARRIS, L. D. 1984. The Fragmented Forest. Island Biogeography Theory and the Preservation of Biotic Diversity. University of Chicago Press, Chicago.

HORN, H. S. 1974. The ecology of secondary succession. Ann. Rev. Ecol. Syst. 1974:25-37.

HUECK, K. 1972. As Florestas da América do Sul. Editora Polfgono, São Paulo, Brasil.

HUNTLY, N. \& R. S. INOUYE. 1987 Small mammal populations of an old-field chronosequence: successional patterns and associations with vegetation. J. Mamm. 68(4):739-745.

ISABIRYE-BASUTA, G. \& J. M. KASENENE. 1987. Small rodent populations in selectively felled and mature tracts of Kibale forest, Uganda. Biotropica 19(3):260-266.

JAMES, F. C. \& N. O. WAMER. 1982. Relationships between temperate forest bird communities and vegetation structure. Ecology 63:159-171.

JOHNS, A. D. \& J. P. SKORUPA. 1987. Responses of rain-forest primates to habitat disturbance: a review. Int. J. Primatol. 8:157-191,

JOHNSON, N. K. 1975. Control of number of bird species on montane islands in the Great Basin. Evolution 29:545-567.

KACHIGAN, S. K. 1982. Multivariate Statiscal Analysis. Radius Press, New York.

KARR, J. R. 1982. Avian extinction on Barro Colorado Island: A Reassessment. Amer. Nat. 119(2):220-239. 
Vol. 6(3), 1989

LACHER, T. E. \& C. J. R. ALHO, in press. Small mammal communities in the Brazilian Pantanal: Population densities, microhabitat affinities and species interactions. J. Mammalogy.

LACHER, T. E., M. A. MARES \& C. J. R. ALHO in press. The structure of a small mammal community in a central Brazilian savanna. In: K. R. REDFORD (ed.), Mammals of the Americas: Essays in Honor of Ralph M. Wetzel. University of Chicago Press, Chicago.

LAEMMERT, H. W., L. C. FERREIRA \& R. M. TAYLOR. 1946. Investigation of Vertebrate Hosts and Arthropod Vectors. Am. J. Trop. Med. 26(suppl.):23-69.

LEIGH, E. G. 1975. Population fluctuations, community stability, and environmental variability. In: M. L. CODY \& J. M. DIAMOND (eds,), Ecology and Evolution of Communities. Harvard University Press, Harvard.

LOMOLINO, M. V. 1984. Mammalian island biogeography: effects of area, isolation and vagility. Oecologia 61:376-382.

LOVEJOY, T. E., R. O. BIERREGAARD, A. B. RYLANDS, J, R. MALCOM, C. E. QUiNTELA, L. H. HARPER, K. S. BROWN, A. H. POWELL, G. V. N. POWELL, H. O. R. SCHUBART \& M. B. HAYS. 1986. Edge and other effects of isolation on Amazon Forest fragments. In : M. E. SOULE (ed.), Conservation Biology. Sinauer Press, Sunderland, Massachussets.

LYNCH, J. F. \& D. F. WHIGHAM. 1984. Effects of forest fragmentation on breeding bird communities in Maryland, USA. Biol. Conserv. 28:287-324.

MacARTHUR, R. H. 1957. On the relative abundance of bird species. Proc. Nat. Acad. Sci. 43:293-295.

MacARTHUR, R. H. 1972. Geographical Ecology. Princeton University Press, Princeton.

MacARTHUR, R. H. \& E. O. WILSON. 1967. The Theory of Island Biogeography. Princeton University Press, Princeton.

MALCOLM, J. 1987. Small mammal abundances in isolated and non-isolated primary forest reserves near Manaus, Brasil. In: Resumos do Congresso Brasileiro de Zoologia, Juiz de Fora, Minas Gerais, Brasil.

MARGULES, C. R. \& M. B. USHER. 1981. Criteria used in assessing wildlife conservation potential: a review. Biol. Conserv. 21:79-109.

MAY, R. M. 1975. Patterns of species abundance and diversity. In: M. L. CODY \& J. M. DIAMOND (eds。), Ecology and Evolution of Communities Harvard Univ. Press, Harvard, Massachussets.

M'CLOSKEY, R. T. 1976. Community structure in sympatric rodents. Ecology 57:728-739. 
MILES, M. A., A. A. de SOUZA \& M. M. POVOA. 1981. mammal tracking and nest location in Brazilian forest with an improved spool-and-line device. J. Zool. Lond. 195:331-347.

MITTER MEIER, R. A., A. F. COIMBRA-FILHO, I. D. CONSTABLE, A. B. RY LANDS \& C. VALLE. 1982. Conservation of primates in the Atlantic forests of Eastern Brazil. Int. Zoo. Yearbook, 1982.

MOOJEN, J. 1952, Os Roedores do Brasil. Instituto Nacional do Livro, Rio de Janeiro, Brazil.

MULLER, P. 1973. The Dispersal Centers of Terrestrial Vertebrates in the Neotropical Realm. W. Junk Publishers, The Hague.

NITIKMAN, L. Z. \& M. A. MARES. 1987. Ecology of small mammals in a gallery forest of Central Brazil. Ann. Carn. Mus. 56:75-95.

PATIL, G. P. \& C. TAILliE. 1983. Diversity as a concent and its measurement. Trans, North. Amer. Wildl. Nat. Resour. Conf. 39:334-353.

PEET, R. K. 1974. The measurement of species diversity. Ann. Rev. Ecol. Syst. 1974:285-307.

PIELCU, E. C. 1974. Population and Community Ecology, Gordon and Breach Publishers, New York.

POOLE, R. H. 1974. An Introduction to Quantitative Ecology. McGraw-Hill, New York,

PRANCE, G. T. 1982. Biological Diversification in the Tropics. Columbia University Press, New York.

QUINN, J. F. \& A. HASTINGS. 1987. Extinction in subdivided habitats. Conserv. Biol. 1:198-208.

ROSENZWEIG, M. L. \& J. WINAKUR. 1969. Population ecology of desert rodent communities: habitats and environmental complexity. Ecology 50:558-572.

SHAFFER, M. L. 1981. Minimum population sizes for species conservation. Bioscience 31:131-134.

SIMBERLOFF, D. S. 1976. Experimental zoogeography of islands: effects of island size. Ecology 57:629-578.

SIMBERLOFF, D. S. 1982. Big advantages of small refuges. Nat. Hist. 91:6-13.

SIMBER LOFF, D. S. \& L. G. ABELE. 1976. Island biogeography theory and conservation pratice. Science 191:285-286. 
Vol. 6(3), 1989

SIMBERLOFF, D. S. \& L. G. ABELE. 1982. Refuge design and island biogeographic theory: effects of fragmentation. Amer. Nat. 120:41-50.

SOKAL, R. R. \& ROHLF, F. J. 1981. Biometry• W. H. Freeman Co॰, New York。

SOULE, M. E. B. 1980. Thresholds for survival: maintaining fitness and evolutionary potential. In: M. E. SOULE \& B. A. WILCOX (eds.), Conservation Biology. Sinauer Press, Sunderland, Massachussets.

SOULE, M. E. B. 1983. What do we really know about extinction? In: C. M. SCHONEWALD-WILCOX, S. M. CHAMBERS, B. MACBRYDE \& L. THOMAS (eds。), Genetics and Conservation. Benjamin Cummings Co., Menlo Park, California.

SOUZA, W. P. 1984. The role of disturbance in natural communities. Ann. Rev. Ecol. Syst. 15:353-391.

STALLINGS, J. R. 1988. S mall mammal comunities of an eastern Brazilian park. $\mathrm{Ph}$. D. Dissertation, University of Florida, Gainesville, Florida.

USHER, M. B. 1986. Wildlife Conservation Evaluation. Chapman and Hall, New York,

WEAVER, M. \& M. KELLMAN. 1981. The effects of forest fragmentation on woodlot tree biotas in Southern Ontario. J. Biogeogr. 8:199-210.

WESTMAN, W. E. 1983. Island biogeography: studies on the xeric shrublands of the inner Channel Islands, California. J. Biogeogr. 10:96-118,

WILliams, C. B. 1964. Patterns in the Balance of Nature. Academic Press, New York.

WILLIS, E. O. 1979. The composition of avian communities in remanescent woodlots in southern Brazil. Papeis Avulsos Zool. 33(1):1-25.

ZIMMERMAN, B. L. \& R. O. BIERREGAARD. 1986. Relevance of the equilibrium theory of island biogeography and species-areas relations to conservation with a case from Amazonia. J. Biogeogr. 13:133-143. 